Article

\title{
Deciphering the Host-Pathogen Interactome of the Wheat-Common Bunt System: A Step towards Enhanced Resilience in Next Generation Wheat
}

\author{
Raghav Kataria ${ }^{1}$ (D) and Rakesh Kaundal ${ }^{1,2,3, *(D)}$ \\ 1 Department of Plants, Soils, and Climate, College of Agriculture and Applied Sciences, Utah State University, \\ Logan, UT 84322, USA; raghav.kataria@usu.edu \\ 2 Bioinformatics Facility, Center for Integrated BioSystems, College of Agriculture and Applied Sciences, \\ Utah State University, Logan, UT 84322, USA \\ 3 Department of Computer Science, College of Science, Utah State University, Logan, UT 84322, USA \\ * Correspondence: rkaundal@usu.edu; Tel.: +1-(435)-797-4117; Fax: +1-(435)-797-2766
}

check for

updates

Citation: Kataria, R.; Kaundal, R. Deciphering the Host-Pathogen Interactome of the Wheat-Common Bunt System: A Step towards Enhanced Resilience in Next Generation Wheat. Int. J. Mol. Sci. 2022, 23, 2589. https://doi.org/ $10.3390 /$ ijms 23052589

Academic Editors: Yuriy L. Orlov, Ming Chen and Oxana

B. Dobrovolskaya

Received: 31 January 2022

Accepted: 9 February 2022

Published: 26 February 2022

Publisher's Note: MDPI stays neutral with regard to jurisdictional claims in published maps and institutional affiliations.

Copyright: (C) 2022 by the authors. Licensee MDPI, Basel, Switzerland. This article is an open access article distributed under the terms and conditions of the Creative Commons Attribution (CC BY) license (https:// creativecommons.org/licenses/by/ $4.0 /)$.

\begin{abstract}
Common bunt, caused by two fungal species, Tilletia caries and Tilletia laevis, is one of the most potentially destructive diseases of wheat. Despite the availability of synthetic chemicals against the disease, organic agriculture relies greatly on resistant cultivars. Using two computational approaches-interolog and domain-based methods-a total of approximately $58 \mathrm{M}$ and $56 \mathrm{M}$ probable PPIs were predicted in T. aestivum-T. caries and T. aestivum-T. laevis interactomes, respectively. We also identified 648 and 575 effectors in the interactions from T. caries and T. laevis, respectively. The major host hubs belonged to the serine/threonine protein kinase, hsp70, and mitogen-activated protein kinase families, which are actively involved in plant immune signaling during stress conditions. The Gene Ontology (GO) and Kyoto Encyclopedia of Genes and Genomes (KEGG) enrichment analysis of the host proteins revealed significant GO terms (O-methyltransferase activity, regulation of response to stimulus, and plastid envelope) and pathways (NF-kappa B signaling and the MAPK signaling pathway) related to plant defense against pathogens. Subcellular localization suggested that most of the pathogen proteins target the host in the plastid. Furthermore, a comparison between unique $T$. caries and T. laevis proteins was carried out. We also identified novel host candidates that are resistant to disease. Additionally, the host proteins that serve as transcription factors were also predicted.
\end{abstract}

Keywords: wheat; Tilletia; common bunt; host-pathogen interactions; effectors; secretory; R-genes; computational prediction

\section{Introduction}

Wheat (Triticum aestivum L.), belonging to the Poaceae family, is one of the most widely cultivated crop species. Being an important staple food, it feeds a large part of the world's population. In terms of global production and plant acreage, wheat ranks third and comprises about 35\% of the total food grain of the world [1]. It is considered as a primary source of carbohydrates, proteins, fiber, and various other minor nutrients, such as minerals, lipids, phytochemicals, and vitamins [2], which makes wheat one of the most favorable food grains worldwide. Wheat is widely grown in a broad range of environments, such as in temperate, tropical, warm/humid, or cold/dry conditions [3]. According to the recent (2021) assessment on wheat production by the FAO (Food and Agriculture Organization), there has been a significant yield gain in wheat production as compared to past years (http:/ / www.fao.org/worldfoodsituation/csdb/en/, accessed on 05 May 2021); however, the increasing population and dietary changes of people are leading to the need for substantial yield gains in the future to meet this escalating demand [4].

Various factors, such as climate change and abiotic and biotic stresses, are a major threat to global wheat production. Diseases and pests contribute to about $20 \%$ of the loss of 
wheat production globally. Among the fungal pathogens, Blumeria graminis, Puccinia species, Fusarium species, and Tilletia species are considered as the most important pathogens, affecting the crop yield to a great extent [5]. Common bunt, the most potentially destructive disease of wheat, is caused by Tilletia caries (syn. Tilletia tritici) and Tilletia laevis (syn. Tilletia foetida). An outbreak of this disease has been observed in countries worldwide, including the United Kingdom [6], Czech Republic [7], Romania [8], and others. Both species are similar in their life cycle and germination and they produce similar disease symptoms [9]. The disease is seed-borne, typically induced by the teliospores of the fungi under favorable conditions, which contaminate the seed surface and infect the coleoptile before the seedling's emergence [10]. Since the grains are replaced with unpleasant-smelling brown to black bunt ball spores, the infected plants lead to reduced grain yield and seed quality in comparison to a healthy plant [11]. Due to the production of trimethylamine, the infected spikes of wheat have a foul odor [12]. The disease can be effectively managed with the fungicidal treatment of the seeds; however, in the case of low-input agriculture, the wide usage of fungicides is not applicable [13].

Molecular interactions form the basis of pathogenicity [14]. Proteins interact with other proteins, either through transient or permanent protein complexes, in order to perform various essential biological functions. In systems biology, inferring the protein-protein interactions (PPIs) between host and pathogen form the basis of understanding for disease infection mechanisms [15]. The prediction of PPIs with the help of bioinformatics techniques enhances the study of protein function and cellular behavior [16]. A wide range of computational approaches, such as phylogenetic profiling, gene ontology (GO) annotation, protein domain interactions, sequence similarity, and others, have been developed for the prediction of host-pathogen interactions (HPIs). Among the available methods, the sequence-based and domain-based approaches are highly preferred for PPI prediction [17]. The computational methods utilize protein-wide PPIs and provide deep insights into the biological processes [18]. Although various experimental techniques are available to detect and validate PPIs, such techniques are time-consuming and labor-intensive [19]. The current study is the first to delineate the PPIs between Triticum aestivum and Tilletia species using two computational approaches-interolog and domain-based methods-on the genome-wide scale followed by a detailed functional enrichment, network visualization, and identification of protein hubs, transcription factors, etc.

\section{Results and Discussion}

The genome-wide protein-protein interactions between T. aestivum and Tilletia species were predicted using two computational approaches: the interolog and domainbased approaches. We employed 112 randomly generated BLAST parameter combinations based on sequence identity $(30 \%, 40 \%, 50 \%$, and $60 \%)$, e-value $\left(1 \times 10^{-4}, 1 \times\right.$ $10^{-5}, 1 \times 10^{-10}, 1 \times 10^{-20}, 1 \times 10^{-25}, 1 \times 10^{-30}$, and $1 \times 10^{-50}$ ) and sequence coverage $(30 \%, 40 \%, 50 \%, 60 \%$, and $80 \%)$. The BLAST combinations and the corresponding interactions found for both the fungal species are presented in Supplementary Material File S1 (Excel Sheets S2 and S3).

For T. aestivum-T. caries, the interactome consisted of 46,557,278 interactions (involving 83,948 host and 4612 pathogen proteins) combined from both the computational approaches, while in T. aestivum-T. laevis, a smaller number of interactions were predicted in the interactome with $44,725,235$ interactions ( 83,942 host and 4380 pathogen proteins). The predicted interactions are available in Supplementary Material File S2 (Excel Sheets S1-S6). Further, the effector proteins and secretory proteins predicted using EffectorP and SignalP, respectively, were collectively identified in the predictions, and referred to as "effectors" throughout the research analysis. In the predicted interactions, 648 T. caries effectors and 575 T. laevis effectors were identified. Therefore, we selected the combination with sequence identity $\geq 30 \%$, e-value $\leq 1 \times 10^{-4}$, and coverage $\geq 40 \%$, based on the maximum number of effectors predicted in this combination as compared to other combinations. The detailed 
predicted PPIs from T. aestivum-T. caries, and T. aestivum-T. laevis interactomes are described in Tables 1 and 2, respectively.

Table 1. Predicted PPIs in T. aestivum-T. caries interactome.

\begin{tabular}{cccc}
\hline Interaction Database & $\begin{array}{c}\text { Number of } \\
\text { Interactions }\end{array}$ & $\begin{array}{c}\text { Number of Host } \\
\text { Proteins }\end{array}$ & $\begin{array}{c}\text { Number of Pathogen } \\
\text { Proteins }\end{array}$ \\
\hline Interolog-based & \\
\hline BioGRID & $11,343,237$ & 51,839 & 3574 \\
\hline DIP & $1,334,228$ & 27,027 & 2404 \\
\hline HPIDB & 48,331 & 6779 & 247 \\
\hline IntAct & $4,768,852$ & 48,915 & 3320 \\
\hline MINT & $1,338,779$ & 23,156 & 2608 \\
\hline PHI-base & 28 & 7 & 3838 \\
\hline STRING & $31,159,410$ & 82,876 & 3872 \\
\hline Total (Interolog) (I) & $\mathbf{3 7 , 7 1 4 , 4 4 2}$ & $\mathbf{8 3 , 6 3 9}$ & 2612 \\
\hline & & Domain-based & 2623 \\
\hline 3DID & $1,221,946$ & 27,342 & 3235 \\
\hline DOMINE & $5,803,329$ & 28,007 & 3396 \\
\hline IDDI & $12,112,523$ & 33,619 & 4612 \\
\hline Total (Domain) (II) & $\mathbf{1 4 , 3 0 7 , 3 6 6}$ & 35,526 & 2401 \\
\hline I and II (combined) & $46,557,278$ & 83,947 & 3867 \\
\hline I and II (consensus) & $5,464,530$ & 30,629 & 3348 \\
\hline Interolog (unique) & $32,249,912$ & 83,637 & \\
\hline Domain (unique) & $8,842,836$ & 34,390 & \\
\hline
\end{tabular}

Total (Interolog) (I): The predicted HPIs from all seven interolog databases were merged and duplicates were removed. Total (Domain) (II): The predicted HPIs from all three domain databases were merged and duplicates were removed. I and II (combined): The predicted HPIs from both the methods were merged and the duplicates were removed. I and II (consensus): From both the methods, the consensus of the predicted HPIs was taken and duplicates were removed. Interolog (unique): The unique HPIs containing the interactions only from the interolog-based method. Domain (unique): The unique HPIs containing the interactions only from the domain-based method.

Table 2. Predicted PPIs in T. aestivum-T. laevis interactome.

\begin{tabular}{cccc}
\hline Interaction Database & $\begin{array}{c}\text { Number of } \\
\text { Interactions }\end{array}$ & $\begin{array}{c}\text { Number of Host } \\
\text { Proteins }\end{array}$ & $\begin{array}{c}\text { Number of Pathogen } \\
\text { Proteins }\end{array}$ \\
\hline \multicolumn{2}{c}{ Interolog-based } \\
\hline BioGRID & $11,003,345$ & 51,985 & 3417 \\
\hline DIP & $1,263,028$ & 26,726 & 2307 \\
\hline HPIDB & 46,117 & 6669 & 227 \\
\hline IntAct & $4,601,434$ & 48,463 & 3183 \\
\hline MINT & $1,278,978$ & 22,970 & 5 \\
\hline PHI-base & 35 & 7 & 2558 \\
\hline STRING & $29,978,511$ & 82,878 & 3697 \\
\hline Total (Interolog) (I) & $\mathbf{3 6 , 3 3 0 , 0 2 3}$ & $\mathbf{8 3 , 6 3 7}$ & \\
\hline
\end{tabular}


Table 2. Cont.

\begin{tabular}{|c|c|c|c|}
\hline Interaction Database & $\begin{array}{l}\text { Number of } \\
\text { Interactions }\end{array}$ & $\begin{array}{c}\text { Number of Host } \\
\text { Proteins }\end{array}$ & $\begin{array}{c}\text { Number of Pathogen } \\
\text { Proteins }\end{array}$ \\
\hline \multicolumn{4}{|c|}{ Domain-based } \\
\hline 3DID & $1,151,885$ & 27,110 & 2483 \\
\hline DOMINE & $5,491,200$ & 27,901 & 2502 \\
\hline IDDI & $11,548,603$ & 33,704 & 3063 \\
\hline Total (Domain) (II) & $13,642,742$ & 35,591 & 3212 \\
\hline I and II (combined) & $44,725,200$ & 83,941 & 4380 \\
\hline I and II (consensus) & $5,247,565$ & 30,659 & 2305 \\
\hline Interolog (unique) & $31,082,458$ & 83,634 & 3692 \\
\hline Domain (unique) & $8,395,177$ & 34,176 & 3164 \\
\hline \multicolumn{4}{|c|}{$\begin{array}{l}\text { Total (Interolog) (I): The predicted HPIs from all seven interolog databases were merged and duplicates were } \\
\text { removed. Total (Domain) (II): The predicted HPIs from all three domain databases were merged and duplicates } \\
\text { were removed. I and II (combined): The predicted HPIs from both the methods were merged and the duplicates } \\
\text { were removed. I and II (consensus): From both the methods, the consensus of the predicted HPIs was taken } \\
\text { and duplicates were removed. Interolog (unique): The unique HPIs containing the interactions only from } \\
\text { the interolog-based method. Domain (unique): The unique HPIs containing the interactions only from the } \\
\text { domain-based method. }\end{array}$} \\
\hline
\end{tabular}

\subsection{HPIs from the Common Subnetwork (T. aestivum vs. T. caries/T. laevis)}

As discussed in the Materials and Methods section, using the ortholog approach, we obtained 423 proteins from both the Tilletia species that are orthologs of each other. Subsequently, we identified 79,758 host proteins interacting with these fungal protein orthologs. These proteins were involved in 5,075,732 interactions (referred to as the common subnetwork), which were then taken into consideration for various functional and network analyses.

\subsubsection{Protein Hubs Reveal the Major Proteins Involved in the Infection Mechanism}

The simultaneous physical interactions between proteins are responsible for the accomplishment of their functions. Therefore, the knowledge of interaction mechanisms is crucial to better understand biological processes [20]. Biological networks enable us to identify the important hubs, and help us to understand their role in various biological processes and molecular mechanisms [21]. In addition, the identification of such interactions is likely to give an indication of the functions of those proteins with unknown functions. To determine the major hubs from the common subnetwork, the node degree was taken into consideration, which is briefly described below.

\subsubsection{Degree}

On an average, the degree of T. aestivum and Tilletia proteins (orthologs) was found to be 64 and 11999, respectively (Supplementary Material File S3, Excel Sheets S1 and S2). As expected, the degree of pathogen proteins was observed to be significantly higher than that of the host proteins in the common subnetwork. In the study, a large number of protein hubs were identified from the common subnetwork, of which the top 20 hubs from each species have been discussed below.

\subsubsection{Tilletia Hubs}

In the common subnetwork, the pathogen hubs (Supplementary Material, Figure S1A) showed that a ubiquitin-like domain formed the largest hub, involving Tilletia proteins OAJ10932/KAE8196026.1 and OAJ25570/KAE8207011.1. A previous study demonstrated the role of ubiquitin-like activating enzymes, BcAtg3 (E2) and BcAtg7 (E1), in the fungus Botrytis cinerea. A yeast two-hybrid system confirmed the physical interaction of both the enzymes. Further, the involvement of BcATG3 and BcATG7 was found to be essential in the 
process of autophagy, sclerotial formation, and virulence of $B$. cinerea [22]. Another cluster consisting of OAJ21901/KAE8193768.1, OAJ25001/KAE8207462.1, OAJ08159/KAE8180887.1, OAJ23224/KAE8204607.1, OAJ26348/KAE8189728.1, OAJ27126/KAE8208298.1, OAJ27114/ KAE8206812.1, OAJ25550/KAE8196914.1, and OAI98851/KAE8183999.1 proteins was found to participate in the small GTPase domain and the small GTP-binding protein domain. Small GTPases, such as Rho, Ran, and Ras, are well characterized and known for the regulation of fungal virulence and the production of ROS species, which are essential biological features of fungal colonization in plants [23]. qRT-PCR analysis of PsRan, a Ran gene from Puccinia striiformis f. sp. tritici (Pst), revealed increased transcript levels of PsRan in wheat leaves after inoculation with Pst. The study also showed the involvement of PsRan in fungal growth and development [24]. Rho3, MoMsb2, Erl, and Ras2 play important roles in the appressoria formation and virulence of Magnaporthe oryzae [25,26]. A cluster of pathogen proteins, OAJ23752/KAE8187483.1, OAJ10309/KAE8196172.1, and OAJ11697/KAE8188801.1, is involved in a ubiquitin-conjugating enzyme family. The protein hub "OAJ26088/KAE8189542.1" plays a role in the small ubiquitin-related modifier (SUMO)-conjugating enzyme Ubc9. A study on the rice blast fungus Magnaporthe oryzae suggested that SUMO-conjugating enzymes are important for the process of SUMOylation, which regulates fungal growth and pathogenicity [27]. The protein hub OAJ25070/KAE8192066.1 was found to belong to the AAA-ATPase domain. Another hub of pathogen proteins (OAJ15999/KAE8183760.1, OAJ15730/KAE8206910.1) was involved in the thioredoxin domain. A study on Fusarium graminearum showed that FgTRR, an ortholog of thioredoxin reductase (TRR), is located in the cytoplasm and involved in the virulence of the pathogen [28]. Two proteins, OAJ24420/KAE8208796.1 and OAJ25043/KAE8192521.1, belonged to the RNA recognition motif/RNA-binding domain. In Verticillium dahliae, the RNA-binding protein (VdNop12) was found to be crucial for cold adaptation and causing pathogenesis in cotton plants [29]. Similarly, RNA-binding proteins were found to play a role in pathogenic development in Ustilago maydis [30].

\subsubsection{Triticum aestivum Hubs}

The analysis of protein hubs revealed that all the host protein hubs (Supplementary Material, Figure S1B) were found to be protein kinases. The most interconnected host hubs (TraesCS4D02G250600.1.cds1, TraesCS7A02G437400.1, TraesCS3A02G306000.1, TraesCS5A02G255500.1.cds1, TraesCS5D02G263800.1.cds1, TraesCS5B02G254600.1.cds1, TraesCS4B02G260700.1.cds1, TraesCS2D02G120200.1, and TraesCS2A02G577400.1) belonged to the serine/threonine (Ser/Thr) protein kinase family. Ser/Thr protein kinases play an essential role in the plant stress response by regulating different signaling pathways. SnRK2, a subfamily of SnRK Ser/Thr protein kinases, is involved in the ABA signal transduction pathway during salt stress [31]. In tomato, a Ser/Thr kinase-encoding gene (Pto) was reported to confer resistance against bacterial speck disease. Pto was further found to specifically phosphorylate Pto-interacting 1 (Pti1), and the expression of the Pti1 transgene resulted in an accelerated hypersensitive response in tobacco against Pseudomonas syringae pv. tabici expressing avrPto [32]. The host hub "TraesCS6D02G339600.1", interacting with 290 pathogen proteins, belonged to the heat shock protein (Hsp) 70 family. Heat shock proteins are considered as critical in the plant's response to various environmental stresses and disease resistance. In tobacco, Hsp70 proteins were suggested to be involved in the unfolded protein response (UPR) during biotic and abiotic stresses [33]. A study revealed that the isoforms of Hsp70 and Hsc70 transcripts were found to be highly induced during infection with Nicotiana benthamiana that causes cucumber necrosis virus [34]. The protein hub "TraesCS6B02G232400.1" contains the mitogen-activated protein kinase kinase kinase (MAPKKK) NPK1. The MAPK pathway comprises three different protein kinases (MAPKKK, MAPKK, and MAPK) involved in phosphorylation reactions, resulting in the induction of immune responses in the cell [35]. In Arabidopsis, MAPKKK-dependent MAPK cascades (MEKK-1-MKK1/MKK2-MPK4) are reported to be positive regulators of the innate immune responses against the necrotrophic fungus 
Botrytis cinerea and the bacteria P. syringae pv. tomato DC3000 [36]. In another study, the constitutive expression of tobacco MAPKKK (NPK1) in transgenic maize showed increased drought tolerance [37]. Further, the NPK1 gene, a MAPKKK ANP orthologue, was shown to be actively involved in multiple stress conditions in plants [38]. Seven protein hubs (TraesCS7A02G352200.1, TraesCS3D02G295900.1, TraesCS6B02G162900.1.cds1, TraesCS3B02G330500.1, TraesCS4B02G168200.1.cds1, TraesCS3A02G135700.1.cds1, and TraesCS4D02G179700.2) were annotated as CBL-interacting protein kinases (CIPKs), which are known to regulate numerous cell signals and enhance stress tolerance in plants [39]. Researchers have previously determined the role of TaCIPK10, a CIPK homologue gene, in wheat resistance to Puccinia striiformis f. sp. tritici. TaCIPK10 was immediately induced upon infection with Puccinia striiformis and salicylic acid treatment. Further, TaCIPK10 was found to positively regulate wheat resistance against Puccinia striiformis by transmitting $\mathrm{Ca}^{2+}$ signals [40]. Moreover, the analysis revealed that the host hubs TraesCS2D02G104200.1 and TraesCS2A02G104500.1 belonged to the AGC protein kinase family. Although little information is available on the function of AGC kinases, they are suggested to function in the regulation of growth and the plant defense response against various pathogens. TaAGC1, a wheat AGC kinase gene, was found to be a positive regulator against infection with the fungus Rhizoctonia cerealis. TaAGC1 showed enhanced expression in the resistant wheat line CI12633, while reduced expression was observed in the susceptible line Wenmai 6 [41].

The hub network (Figure 1) analysis revealed that, based on degree, the top 20 pathogen proteins are involved in interaction with the top 20 host proteins, suggesting that the pathogens primarily hijack the protein kinase machinery in the host, thus controlling various processes of the plant immune system. The host protein hubs play a role in plant defense, while the pathogen proteins are involved in the processes that enhance fungal development and pathogenicity. Studying the interactions between the potential host and pathogen proteins can further help understand the infection mechanism, and how the pathogens evolve inside the host.

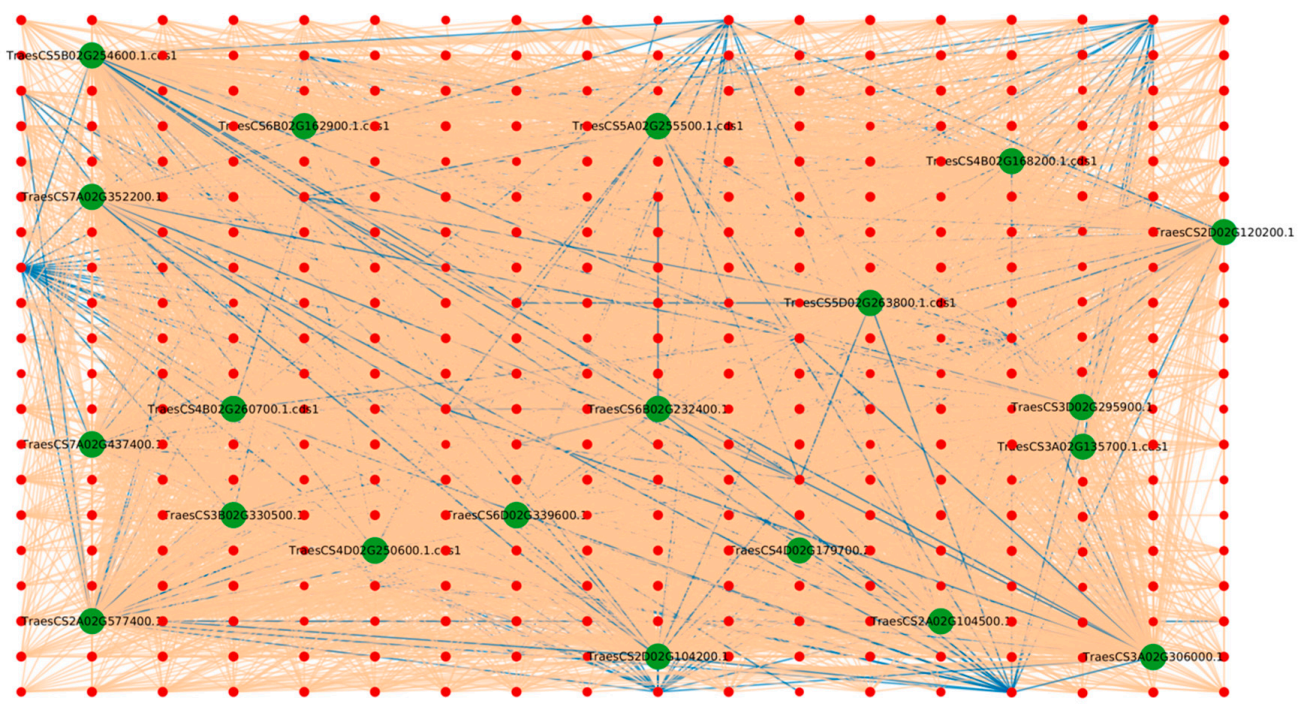

Figure 1. Protein-protein interaction network for the top 20 host protein hubs. Green nodes represent host proteins and red nodes are pathogen proteins. Orange edges depict the interactions from the interolog-based approach, while blue edges belong to the domain-based approach.

\subsection{GO Enrichment Analysis of the Proteins Involved in the Interactions}

The GO enrichment analysis of the host and pathogen proteins involved in the common subnetwork was performed using the enrichment score $[-\log 10(p$-value $)]$. The enrichment analysis of pathogen proteins revealed that 423 pathogen proteins were enriched in $578 \mathrm{GO}$ terms representing the three GO categories (biological process, cellular component, and molecular function) (Supplementary Material, Figure S2). In the molecular function cat- 
egory, the highly enriched GO terms were GTPase activity (GO:0003924), peptidase activity (GO:0008233), and hydrolase activity (GO:0004553). The biological process category comprises proteolysis (GO:0006508), carbohydrate metabolic process (GO:0005975), and protein peptidyl-prolyl isomerization (GO:0000413). Apart from this, the over-represented GO terms in the cellular component category involved endoplasmic reticulum (GO:0005783), ribosome (GO:0005840), and respirasome (GO:0070469). The over-represented GO terms suggest the role of pathogen proteins in increased pathogen virulence, colonization, and the suppression of the plant defense mechanism, which has previously been validated in the literature $[42,43]$. The detailed GO enrichment of Tilletia species proteins is available in Supplementary Material File S3 (Excel Sheet S3), along with other important parameters, such as protein count and adjusted $p$-value.

On the other hand, 79,758 common wheat proteins involved in interactions with the pathogen proteins in the common subnetwork were enriched in 3562 GO terms (Supplementary Material File S3, Excel Sheet S4). The top 15 GO terms from each GO category are represented in Figure 2. The most enriched GO terms in the biological process category involved gametophyte development (GO:0048229), pollen development (GO:0009555), and planttype cell wall organization or biogenesis (GO:0071669). Ubiquitination, a process involved in various plant defense signaling pathways [44], requires three ubiquitin-conjugating enzymes, viz. E1, E2, and E3, to form the isopeptide bond. A study on Arabidopsis revealed the involvement of UBC22, belonging to the E2 subfamily, in female gametophyte development [45]. Osg1, a $\beta$-1,3-glucanase-encoding gene, showed its expression during the early microspore and middle microspore stages in the floret. Upon silencing the expression of Osg1, male sterility was observed in transgenic rice, thus showing its role in male gametophyte development. $\beta$-1,3-glucanases play a significant role in defending the plant by degrading the cell wall of fungal pathogens [46]. In wheat, a higher expression of $\beta$-1,3-glucanase was observed in the resistant genotype in response to spot blotch disease as compared to the susceptible genotype [47].

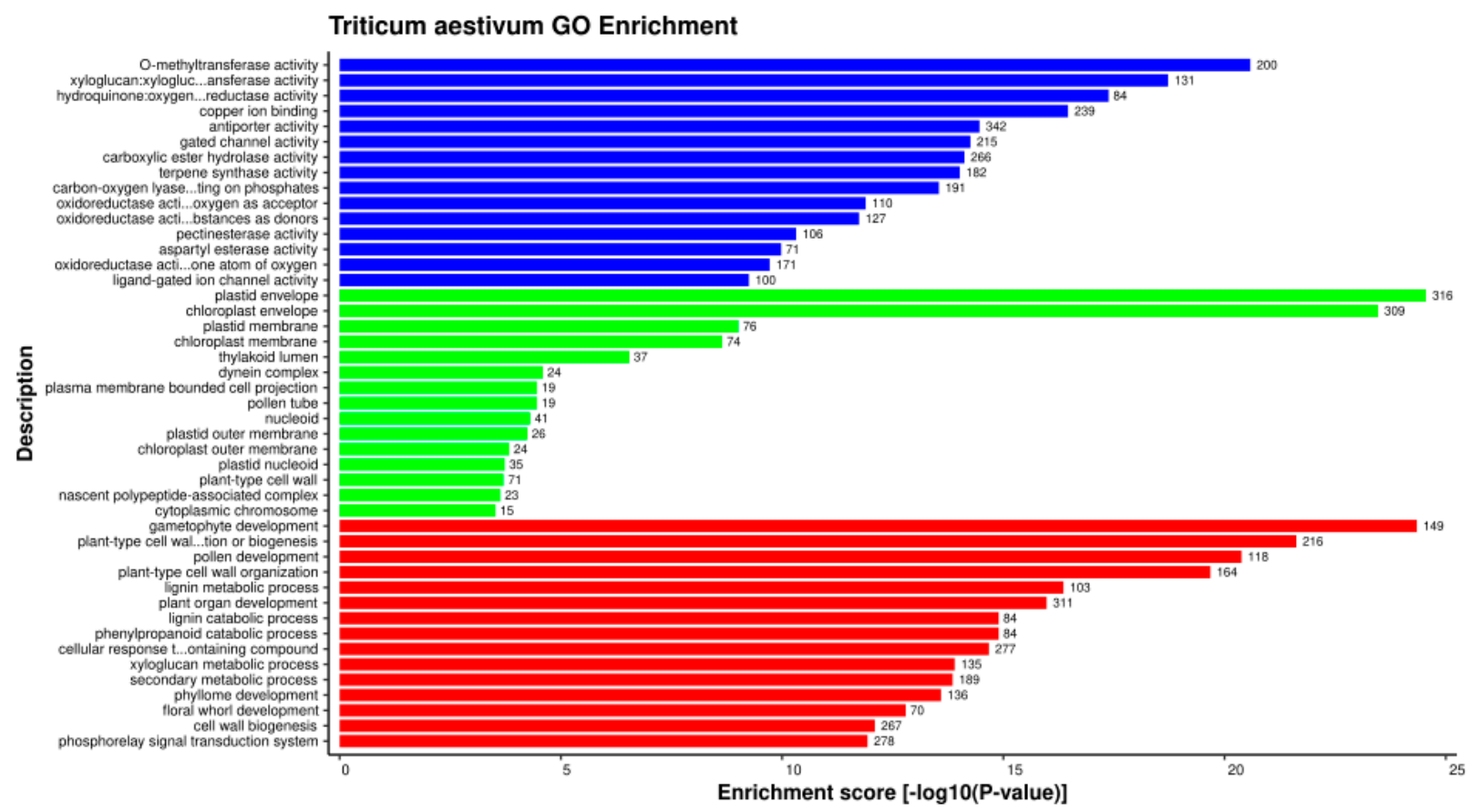

Figure 2. Over-representation of the top 15 GO terms (from each GO category) of host proteins based on enrichment score showing molecular function (blue), cellular component (green), and biological process (red).

In the cellular component category, the proteins were found to be enriched in the plastid envelope (GO:0009526), chloroplast envelope (GO:0009941), and plastid membrane 
(GO:0042170). Hydroperoxide lyase (HPL), localized in outer envelope of the plastid, catalyzes C6-aldehydes, which are explicitly involved in pathogen defense [48,49]. In Arabidopsis, studies report that upregulated AtHPL expression was observed during fungal attack by Botrytis cinerea, which further led to increased levels of C6-aldehydes at the site of pathogen penetration, thus inhibiting the growth of the pathogen [50]. The inner envelope membrane of the chloroplast serves as the site for the synthesis of $\alpha$ tocopherol and plastoquinone-9 [51], which are reported to be involved in plant defense mechanisms. $\alpha$-tocopherols are essential antioxidants that prevent disease in plants by functioning in various processes, such as intracellular signaling and the activation of defense responses in stress conditions [52]. Mesembryanthemum crystallinum plants, when treated with Botrytis cinerea, showed that plastoquinone regulates plant biotic stress in the redox state, and an accelerated hypersensitive-like response was observed in the reduced state of plastoquinone [53].

In the molecular function category, O-methyltransferase activity (GO:0008171), xyloglucan:xyloglucosyl transferase activity (GO:0016762), and hydroquinone:oxygen oxidoreductase activity (GO:0052716) were found to be abundant. Various plant secondary metabolites, such as alkaloids, flavonoids, and phenylpropanoids, catalyzed by S-adenosyl-L-methioninedependent O-methyltransferases (OMTs), play critical roles in plant growth and development [54]. An important class of OMTs, caffeic acid 3-O-methyltransferases (COMTs; EC 2.1.1.6), are involved in lignin biosynthesis. At the time of plant-pathogen interaction, lignin deposition in the cell wall simultaneously acts as a physical barrier against pathogens, increases the host's resistance to toxins, and restricts the diffusion of nutrients from the host to the pathogens [55]. When inoculated with the necrotrophic fungus Rhizoctonia cerealis, a wheat COMT gene, TaCOMT-3D (localized in chromosome 3D), showed increased levels of expression. The silencing of TaCOMT-3D showed a high susceptibility to sharp eyespot disease, while the overexpression of TaCOMT-3D enhanced the resistance of transgenic wheat lines against the disease. The overexpression of TaCOMT-3D also led to an increase in lignin accumulation [56]. In our study, we identified six proteins (Figure 3) belonging to T. aestivum chromosome 3D (TraesCS3D02G392500.1, TraesCS3D02G540200.1, TraesCS3D02G047700.1, TraesCS3D02G047800.1, TraesCS3D02G138700.1, and TraesCS3D02G292000.1), that are involved in O-methyltransferase activity, thus providing strong evidence for their role in the plant defense against fungal disease. A study on Arabidopsis quinone reductases (QRs), $N q r$ and Fqr, revealed an altered interaction between QR knockout $(\mathrm{KO})$ lines and the necrotrophic fungi Botrytis cinerea and Sclerotinia sclerotium, whereby the KO lines (nqr- and $\mathrm{fqr1}^{-}$) were found to be less susceptible to the fungi when compared to the wild-type lines, while the overexpression line $\mathrm{FQR} 1^{+}$showed an increased hypersensitive response against the pathogens [57].

Further, the network analysis of the top GO terms for each category revealed that the host protein "TraesCS7B02G392600.1" was found to be enriched both in gametophyte development (GO:0048229) (Figure 4) and the plastid envelope (GO:0009526) (Figure 5), interacting with 105 pathogen proteins. The TraesCS7B02G392600.1 protein was also found to be involved in other GO terms, including response to osmotic stress (GO:0006970), response to salt stress (GO:0009651), ATP biosynthetic process (GO:0006754), plant-type vacuole (GO:0000325), proton-transporting V-type ATPase (GO:0033180), ion channel activity (GO:0005216), and enzyme binding (GO:0019899). Additionally, this protein also showed involvement in oxidative phosphorylation (ko00190) and the mTOR signaling pathway (ko04150). The results imply that this protein is highly involved in plant defense mechanisms and plays a role in various biological processes during stress conditions. In addition, 105 pathogen proteins interacting with the above-mentioned host were involved in GTPase activity (GO:0003924), exopeptidase activity (GO:0008238), proteolysis (GO:0046034), small GTPase mediated signal transduction (GO:0007264), and the inner mitochondrial membrane protein complex (GO:0098800). These interactions can be considered as potential candidates for experimental analysis, thus providing insights into the infection mechanism and other biological processes pertaining to the disease. 


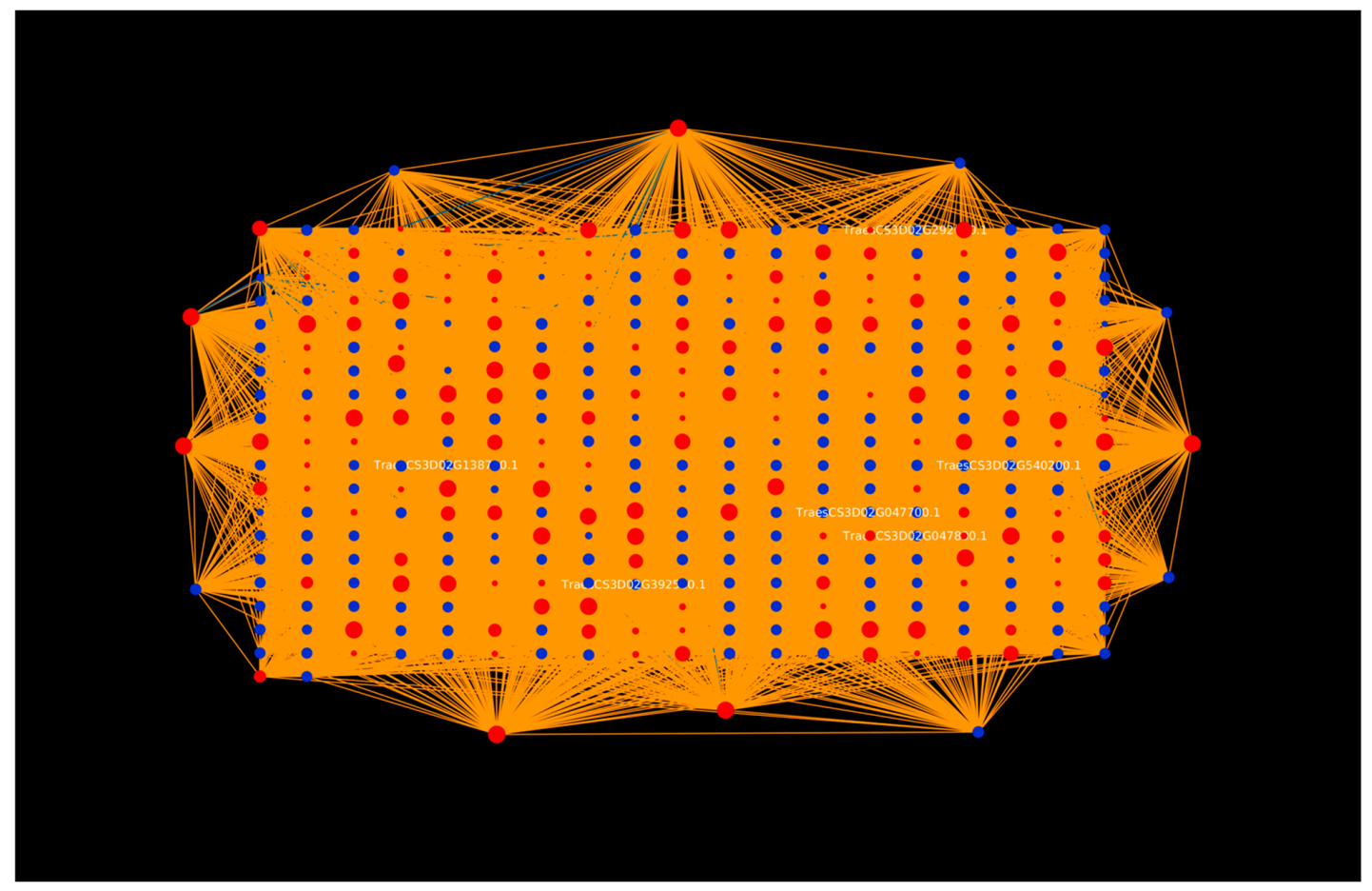

Figure 3. Visualization of top GO term (GO:0008171, O-methyltransferase activity) from the molecular function category. Blue nodes represent host proteins, red nodes are pathogen proteins. Orange edges depict the interactions from the interolog-based approach, while blue edges belong to the domain-based approach.

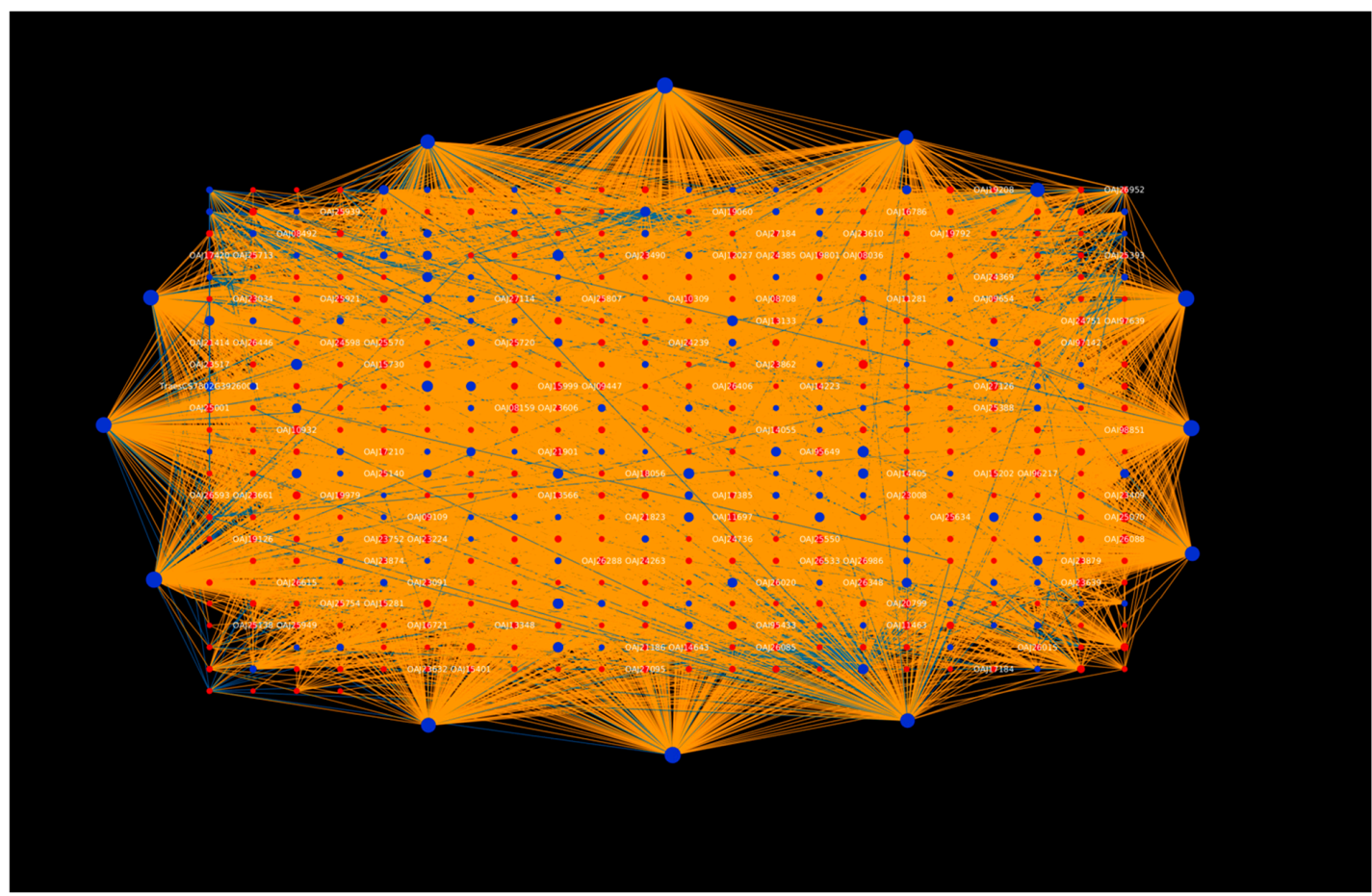

Figure 4. Visualization of the top GO term (GO:0048229, gametophyte development) from the biological process category. Blue nodes represent host proteins, red nodes are pathogen proteins. Orange edges depict the interactions from the interolog-based approach, while blue edges belong to the domain-based approach. 


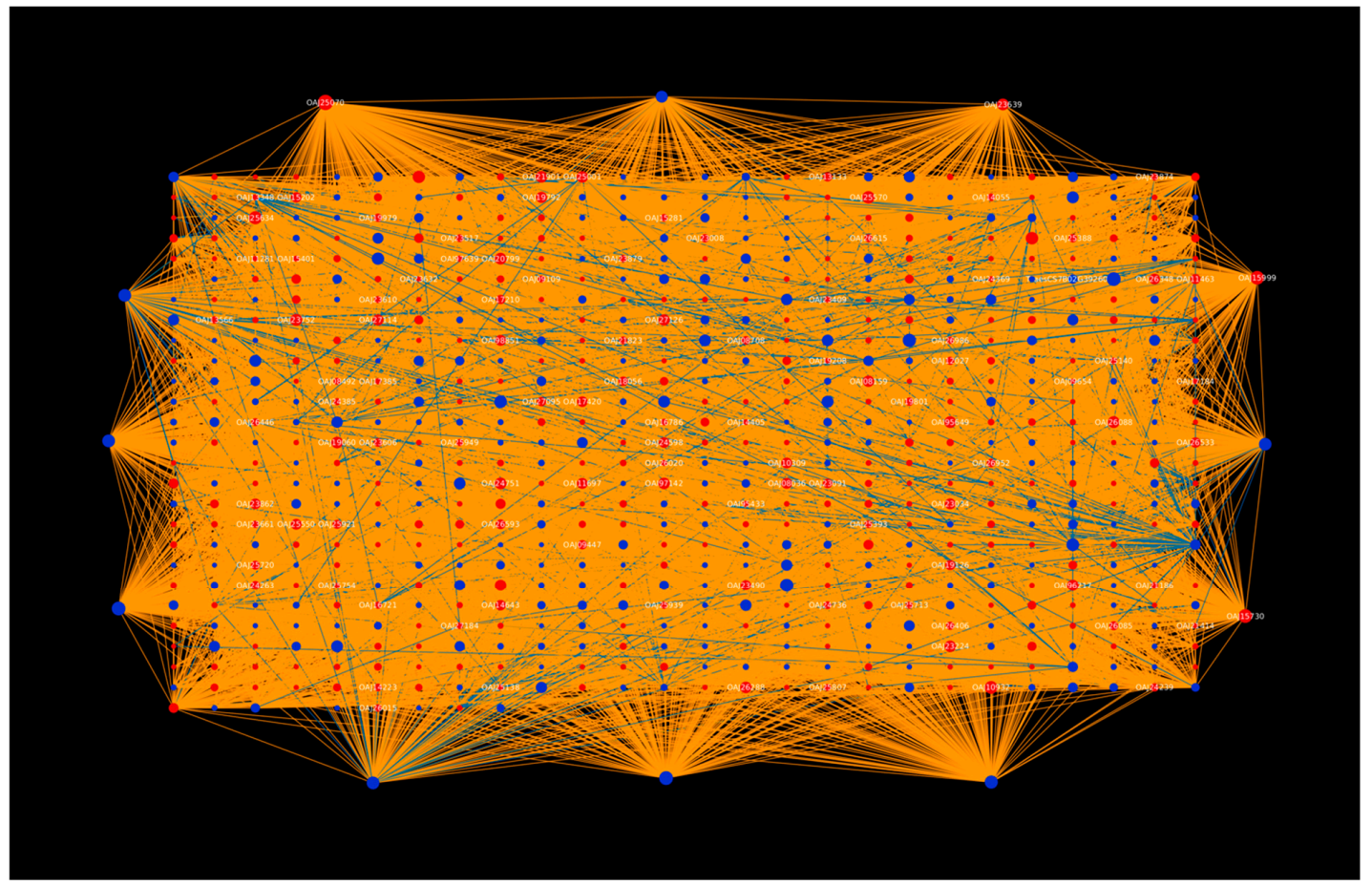

Figure 5. Visualization of the top GO term (GO:0009526, plastid envelope) from the cellular component category. Blue nodes represent host proteins, red nodes are pathogen proteins. Orange edges depict the interactions from the interolog-based approach, while blue edges belong to the domain-based approach.

\subsection{Analysis of Over-Represented KEGG Pathways}

KEGG enrichment provides in-depth understanding of the proteins, which play a role in different biological pathways. In line with this, KEGG enrichment analysis of the host and pathogen proteins involved in the common subnetwork was performed. The pathogen proteins were found to be enriched in 257 KEGG pathways (Supplementary Material File S3, Excel Sheet S5) involving plant hormone signal transduction (ko04075), MAPK signaling pathway-plant (ko04016), protein processing in endoplasmic reticulum (ko04141), and NOD-like receptor signaling pathway (ko04621). The top 20 enriched pathways for pathogen proteins are shown in Supplementary Material, Figure S3.

KEGG pathway enrichment analysis demonstrated that the host proteins interacting with the Tilletia proteins were over-represented in 399 pathways (Supplementary Material File S3, Excel Sheet S6), of which the top 20 pathways are represented in Figure 6. The highly enriched pathways included the NF-kappa B signaling pathway (ko04064) (Figure 7), Toll-like receptor signaling pathway (ko04620), and the MAPK signaling pathway-plant (ko04016). The transcription factor nuclear factor kappa B (NF- $\mathrm{KB}$ ) is reported to regulate immune responses against various extracellular stimuli (such as pathogens) or intracellular stress signals [58]. A study on Arabidopsis NIM1 gene mutants suggested the interaction of the NIM1 protein with NF-KB-related transcription factor, which helps in the induction of systemic acquired resistance (SAR) gene expression and also triggers gene-for-gene resistance against the disease [59]. Further, the Toll-like receptors (TLRs) activate the genes that are responsible for the initiation of immune responses in plants [60]. Mitogenactivated protein kinases (MAPKs), a class of conserved protein kinases, are known to play a critical role in signaling mechanisms during various environmental stresses by associating extracellular stimuli with intracellular responses [61]. In rice, MAPKs have been reported to show resistance against leaf blight disease, caused by Xanthomonas oryzae. The overexpression of rice group C MAPK (OsMPK7) and its upstream MAPK kinase (OsMKK3) in leaves and roots showed inhibition against $X$. oryzae infection, while the silencing of 
OsMPK7 accounted for disease susceptibility [62]. The enrichment analysis results indicate that the host proteins are involved in the pathways related to the generation of defenserelated signals against various stresses, while the pathogen proteins are associated with the pathways that regulate the pathogenesis and metabolism of fungal proteins inside the host cell. Both the host and pathogen proteins were found to be enriched in the MAPK signaling pathway, suggesting a potential crosstalk between the host and pathogen.

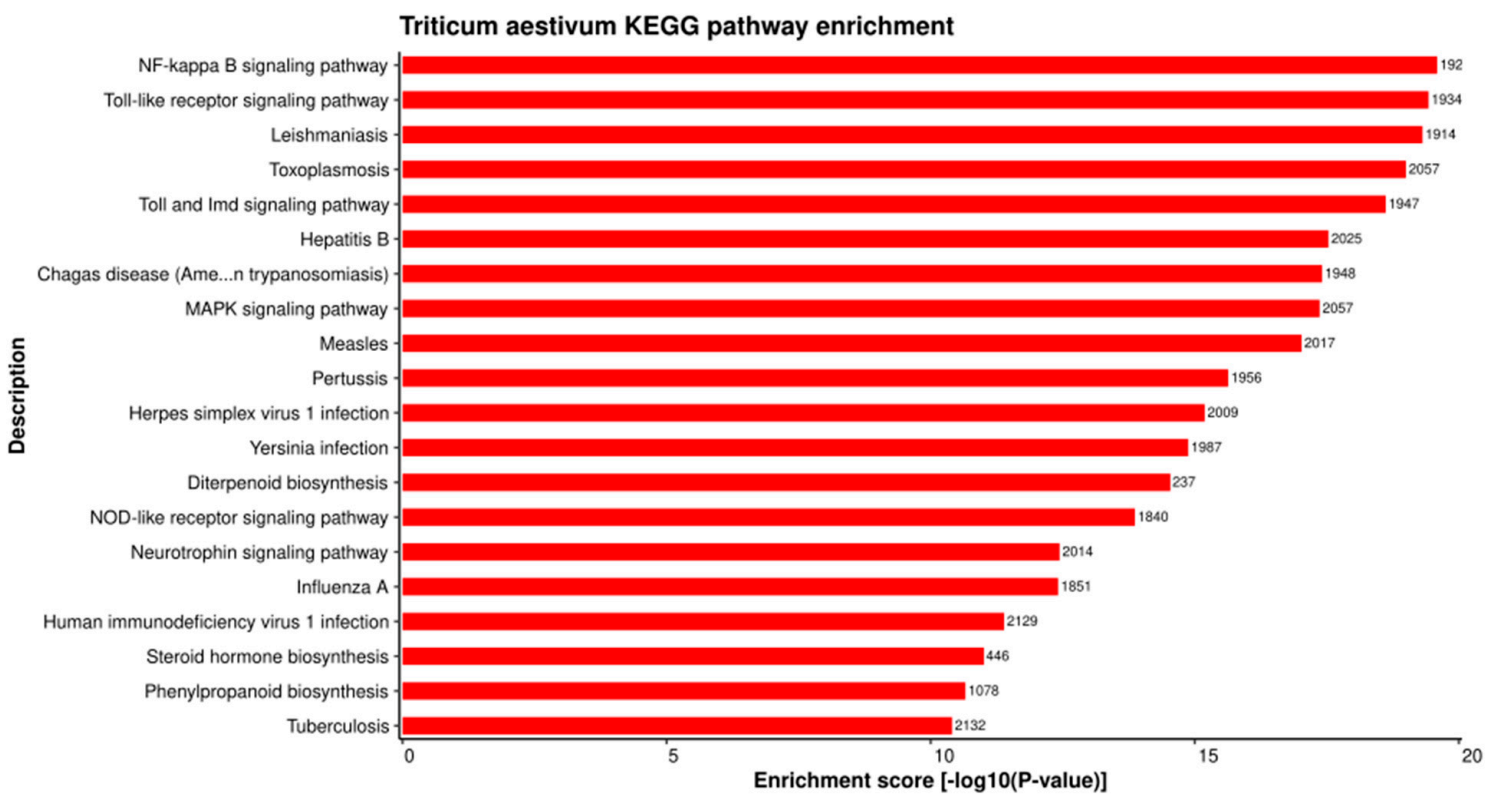

Figure 6. KEGG pathway enrichment analysis of the host proteins involved in HPIs. Top 20 pathways are represented on the basis of enrichment score.

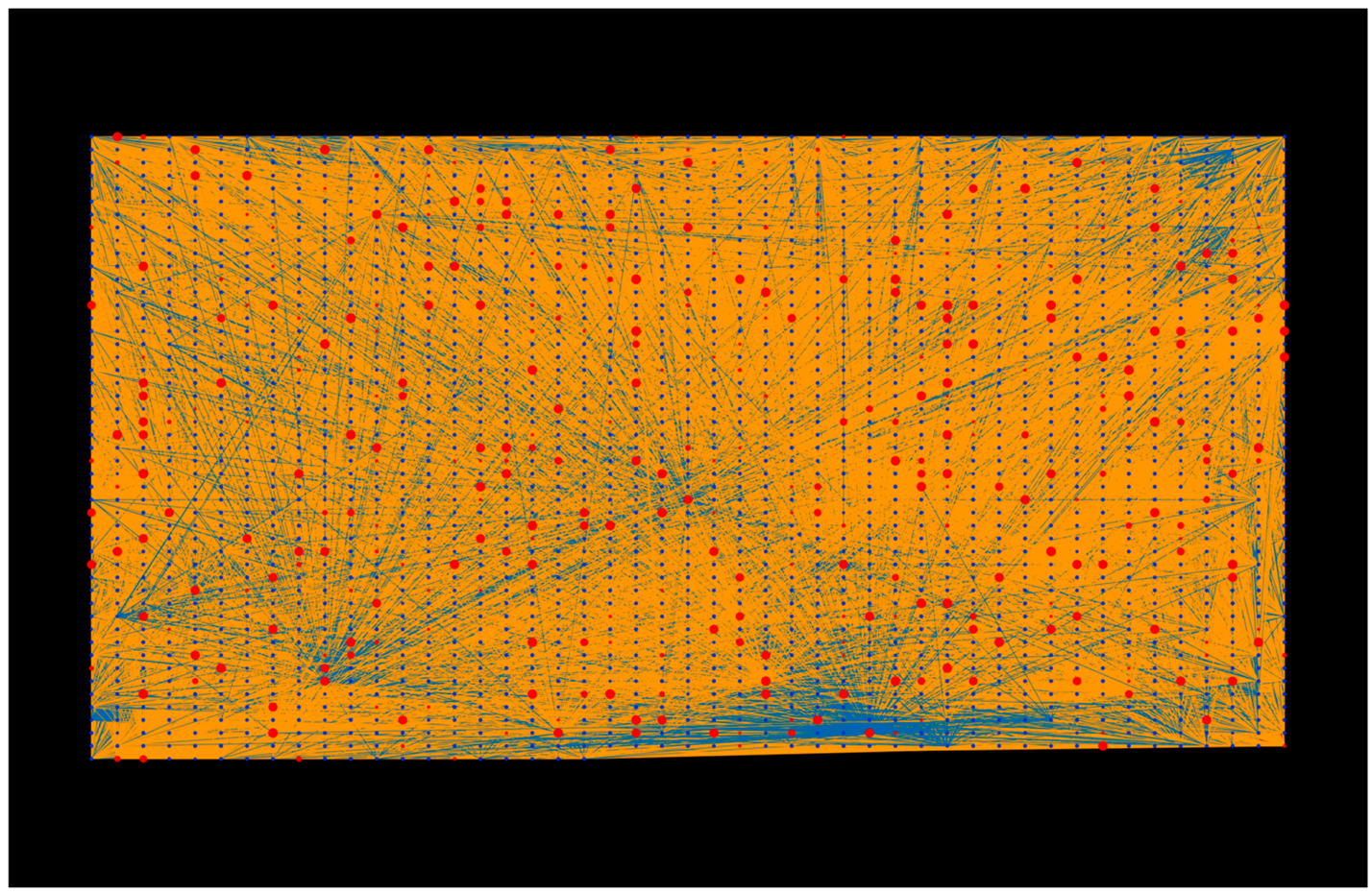

Figure 7. Visualization of the top KEGG pathway (ko04064, NF-kappa B signaling). Blue nodes represent host proteins, red nodes are pathogen proteins. Orange edges depict the interactions from the interolog-based approach, while blue edges belong to the domain-based approach. 


\subsection{The Majority of Host-Pathogen Interactions Were Localized in the Plastid of Host Cells}

Living cells involve a complex machinery that sorts and sends newly synthesized proteins into final locations (compartments) in the cell [63]. The subcellular localization of proteins is a basic part in the quest of determining the function of proteins within the cellular compartment. Protein subcellular localization also gives an inference about the pathway to which an enzyme belongs [64].

In our analysis, the subcellular location of T. aestivum and Tilletia species proteins was predicted to gain better insights into the location of host-pathogen interactions. We found that the majority of the pathogen proteins in the common subnetwork were either extracellular $(25.29 \%)$ or localized in the cytoplasm $(26.24 \%)$ and mitochondria $(15.6 \%)$, followed by the cell membrane $(10.16 \%)$, endoplasmic reticulum $(8.04 \%)$, nucleus $(7.56 \%)$, plastid $(2.4 \%)$, peroxisome $(2.4 \%)$, lysosome $(1.41 \%)$, and Golgi apparatus $(0.94 \%)$ (Figure $8 \mathrm{~A})$. The subcellular localization of ubiquitin-like activating enzymes (BcAtg3 and BcAtg7) in Botrytis cinerea was determined using fluorescence assays, which revealed that both the enzymes were localized in the cytoplasm [22]. In Saccharomyces cerevisiae, the pathogenesisrelated thioredoxin reductases were found to be localized in the cytoplasm and mitochondria $[65,66]$.

A

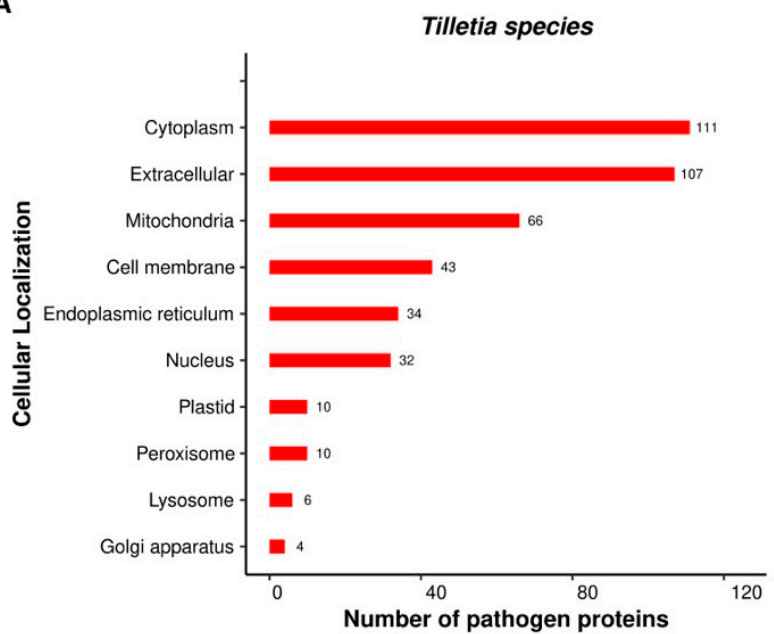

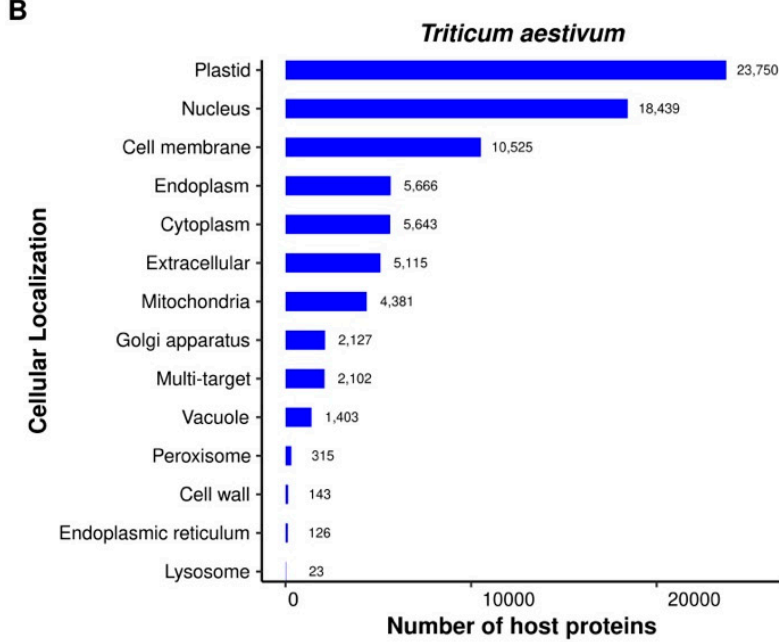

Figure 8. Subcellular localization of the pathogen proteins (A) and host proteins (B) involved in the common subnetwork.

On the other hand, the host proteins associated with fungal proteins in the interactions were mostly located in the plastid $(29.77 \%)$, nucleus $(23.12 \%)$, and cell membrane $(13.19 \%)$ (Figure 8B). In rice, the OsVQ domain proteins were shown to play an important role against various biotic and abiotic stresses. The study postulated that the OsVQ proteins were localized in the nucleus and plastid [67], which is in line with our subcellular localization prediction. A total of 2102 host proteins were found to be localized at multiple sites, implying the role of host proteins in various processes at different locations inside the cell. Such multifunctional proteins are also known as moonlighting proteins [68]. The detailed subcellular localizations of the predicted host and pathogen proteins are available in Supplementary Material File S3 (Excel Sheets S7: Pathogen, and Excel Sheets SS8: Host). Our analysis further suggested that the pathogen proteins targeted host proteins mainly in the plastid (Supplementary Material File S3, Excel Sheet S9).

\subsection{Unique Interactions between Host and Pathogens}

In this study, we were interested in further comparing the species-specific HPIs and the functional differences between T. caries and T. laevis. In line with this, we identified 225 unique T. caries proteins interacting with 78,294 host proteins, accounting for 2,514,109 interactions (Supplementary Material File S4, Excel Sheets S1-S3). On the other 
hand, 152 unique T. laevis proteins were identified that were involved in 1,865,266 interactions with 76,903 host proteins (Supplementary Material File S4, Excel Sheets S4-S6). The comparison between the predicted HPIs suggests that the number of interactions with the host proteins in the case of T. laevis were much less than those of T. caries. Thus, it can be inferred that infection can occur even with a smaller number of interactions between the host and pathogen proteins. Further, we compared the enrichment analysis results of the unique proteins with the common subnetwork.

\subsubsection{Functional Analysis of Unique T. caries Proteins in the Predicted PPIs}

The functional enrichment analysis indicated that most of the over-represented GO terms were similar between the common subnetwork and T. caries. These included the lipid catabolic process (GO:0016042), proteolysis (GO:0006508), triglyceride lipase activity (GO:0004806), GTPase activity (GO:0003924), nucleosome (GO:0000786), and DNA packaging complex (GO:0044815). However, in comparison to the common subnetwork, we also found $70 \mathrm{GO}$ terms that were unique to T. caries, comprising nucleobase-containing compound kinase activity (GO:0019205), phosphotransferase activity (GO:0016776), the regulation of phosphate metabolic process (GO:0019220), and small molecule catabolic process (GO:0044282). For unique KEGG pathways in T. caries, ABC transporters (ko02010) and arginine and proline metabolism (ko00330) were found to be over-represented. The GO and KEGG enrichment analysis for T. caries proteins is detailed in Supplementary Material File S5 (Excel Sheets S1 and S2). Various studies in the past have shown that these GO terms and KEGG pathways aid in pathogen survival and virulence [69-72].

On the other hand, for the host proteins associated with the unique T. caries proteins, only two GO terms were found to be unique, viz. GO:0032367 (intracellular cholesterol transport) and GO:0030301 (cholesterol transport), which are related to humans and do not play a role in the plant defense system. All the enriched KEGG pathways were found to be similar for the host proteins associated with the unique T. caries proteins and the common subnetwork.

\subsubsection{Functional Analysis of Unique T. laevis Proteins in the Predicted PPIs}

The GO enrichment analysis of unique T. laevis proteins revealed analogous patterns, similar to the unique $T$. caries proteins and the common subnetwork. In comparison with the common subnetwork, the unique GO terms associated with T. laevis involved the cellular carbohydrate metabolic process (GO:0044262), regulation of kinase activity (GO:0043549), NAD binding (GO:0051287), oxidoreductase activity (GO:0016627), and cytosol (GO:0005829). We also found a few KEGG pathways unique to T. laevis, for example, isoquinoline alkaloid biosynthesis (ko00950) and arginine and proline metabolism (ko00330). The enrichment analysis for unique T. laevis proteins is available in Supplementary Material File S5 (Excel Sheets S3 and S4).

On the other hand, it was observed that the host proteins associated with the unique T. laevis proteins were enriched in similar GO terms. The GO term "condensed chromosome kinetochore" (GO:0000777) was found to be unique to T. laevis host proteins, and is irrelevant to plants. No KEGG pathway was retrieved that was unique to the host proteins of T. laevis. In addition, the subcellular localization analysis indicated no unique patterns for the localization of the proteins.

\subsection{Novel Host Targets Show Resistance to Common Bunt Disease}

The innate immune system in plants deploys various specialized genes, known as $R$ (resistance) genes, responsible for the detection of pathogens and the initiation of specific immune responses. The recent surge in genomic resources, combined with the advancement in plant breeding programs, has accelerated the identification and cloning of resistance genes in wheat [73]. Due to the complex nature of the hexaploid wheat genome, the study of $\mathrm{R}$ gene evolution provides deeper insights into the immune mechanisms, resulting in novel candidates for disease resistance. 
Researchers in the past have identified common bunt resistance QTLs/SNPs located on different chromosomes in wheat using various genomic techniques, such as genotyping-bysequencing (GBS), genome-wide association study (GWAS), and marker-assisted selection (MAS). A genome-wide association study in wheat identified 15 common bunt resistancerelated SNPs on chromosomes 1B, 2A, 2B, 3D, 4A, 7A, and 7B, of which five potential SNPs were located on chromosomes $2 \mathrm{~A}, 3 \mathrm{D}$, and $4 \mathrm{~A}$ [74]. In another paper, GWAS found 123 SNPs on 14 chromosomes (1A, 1B, 2B, 3A, 3B, 4A, 5A, 5B, 5D, 6A, 6B, 7A, 7B, and 7D) that were associated with the Nebraska race of common bunt resistance. Among those identified, a significant number of SNPs were located on chromosomes 1B (31 SNPs) and 6B (28 SNPs). Some of the identified SNPs on chromosomes $1 \mathrm{~B}$ and $2 \mathrm{~B}$ were also found to be associated with bunt resistance genes (Bt1, Bt4, Bt5, Bt6, Bt12) [75]. Common bunt resistance was also found to be regulated by the QTLs QBt.ifa-1BS, QBt.ifa-1AL, and QBt.ifa$7 A L$ that were mapped to chromosomes $1 \mathrm{~A}, 1 \mathrm{~B}$, and $7 \mathrm{~A}$, respectively. Several major and minor QTLs on chromosome 1B have been mapped, showing that chromosome 1B is highly involved in disease resistance [76]. With the use of genomics and bioinformatics, a wheat R-gene atlas was constructed consisting of resistance genes against wheat pathogens. The R-gene atlas contains 16 genes (Bt1-Bt15, Btp) associated with bunt, and these genes were located on chromosomes $1 \mathrm{~B}, 2 \mathrm{~B}, 2 \mathrm{D}, 3 \mathrm{~B}$, and $6 \mathrm{D}$ [77]. Combining the information from the above-mentioned resources, we identified the proteins belonging to the bunt resistance chromosomes. The analysis resulted in 69,215 host proteins that can serve as novel targets to understand the immune responses implicated by the host proteins during stress conditions. These host proteins were involved in 4,411,628 interactions with 423 pathogen proteins, which can be further considered as potential candidates for further studying the disease mechanism. The maximum number of interactions belonged to chromosome $2 \mathrm{~B}$, followed by chromosomes 2D and 2A. The interactions associated with bunt resistance chromosomes are available in Supplementary Material File S6 (Excel Sheets S1-S18).

\subsection{Identification of Stress-Related Transcription Factors in T. aestivum}

Transcription factors (TFs) are proteins that critically regulate gene expression upon perceiving stress-related signals and further activate defense-related pathways, such as the ABA signaling pathway, salicylic acid signaling pathway, and others [78]. In our analysis, we identified 5455 wheat proteins that served as transcription factors (Supplementary Material File S7, Excel Sheet S1), controlling various defense response signals during biotic and abiotic stresses. The identified proteins were classified into $28 \mathrm{TF}$ families that were highly responsive during environmental cues. These host proteins were found to interact with 334 pathogen proteins, accounting for 322,816 PPIs (Supplementary Material File S7, Excel Sheet S2). According to previous reports, the transcription factor families such as bHLH (basic helix-loop-helix), NAC (NAM, ATAF1/2, and CUC2), MYB (myeloblastosis related), bZIP (basic leucine zipper), ERF (ethylene responsive factor), WRKY, AP2 (APETALA2), and CAMTA (CaM-binding transcription activator) are considered to play a critical role during the defense response against pathogens $[79,80]$.

\section{Materials and Methods}

An overview of the workflow we developed for deciphering the wheat-common bunt PPIs is presented in Figure 9. The detailed steps are described below. 


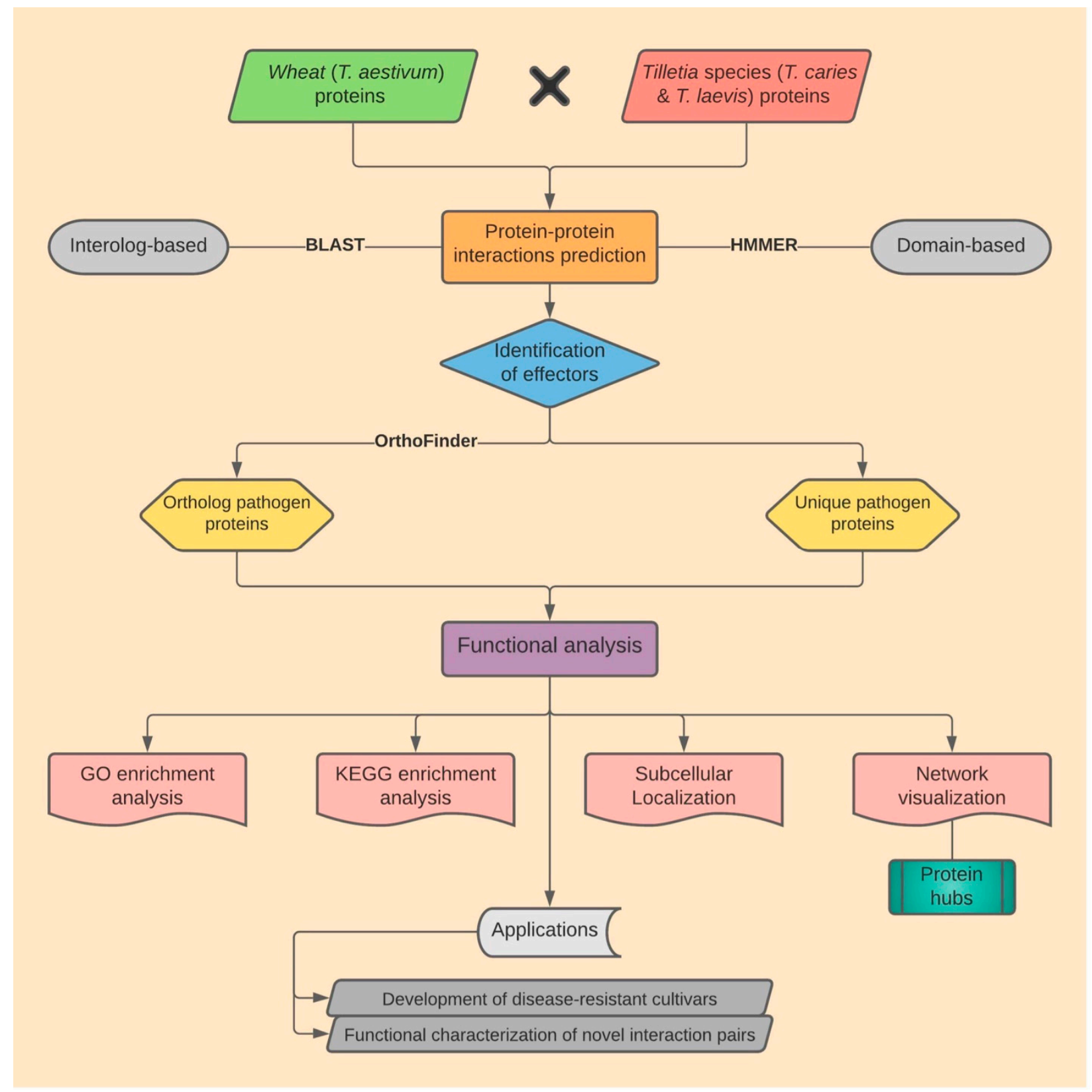

Figure 9. Overall workflow for protein-protein interaction prediction in the wheat-common bunt (T. aestivum-Tilletia sp.) system.

\subsection{Datasets}

The proteomes of Triticum aestivum and the two Tilletia species were collected from different sources: T. aestivum (133,346 proteins) from Ensembl Plants (http:/ / plants.ensembl. org/index.html (accessed on 20 April 2021)), T. caries strain DAOM 238032 (10,204 proteins) from Ensembl Fungi (https:/ / fungi.ensembl.org/index.html (accessed on 20 April 2021)), and T. laevis strain DAOMC 238040 (9651 proteins) from the National Center for Biotechnology Information (NCBI) (https:/ / www.ncbi.nlm.nih.gov/ (accessed on 20 April 2021)). To ensure non-redundancy, the proteomes of the Tilletia species were analyzed with CDHIT [81] at $100 \%$ identity, which resulted in 10,170 T. caries and 9637 T. laevis proteins that were further employed for the prediction of HPIs. Being hexaploid (AABBDD) in nature, a high number of isoforms were found in the wheat proteins. To overcome this complexity, the longest isoforms were considered, followed by the genome-wise segregation of the proteins into genome A, genome B, and genome D proteins. There were 2659 unknown 
proteins that did not belong to any of the genome; hence, these were treated as a separate category. The proteins (genome-wise) were then analyzed with CD-HIT at $100 \%$ identity, which led to 104,701 T. aestivum proteins in total. Throughout the research analysis, the protein accessions initiated with "Traes", "OAJ", and "KAE" refer to T. aestivum, T. caries, and T. laevis proteins, respectively.

To infer the host-pathogen interactions, two approaches were implemented: an interolog-based and a domain-based approach. In the interolog-based approach, seven interaction databases, namely IntAct [82], MINT (Molecular INTeraction database) [83], HPIDB (Host-Pathogen Interaction Database) [84], DIP (Database of Interacting Proteins) [85], BioGRID (Biological General Repository for Interaction Datasets) [86], STRING (Search Tool for the Retrieval of Interacting Genes/Proteins) [87], and PHI-base (Pathogen-Host Interactions database) [88], were employed in the analysis. Each of the above-mentioned databases were downloaded and executed locally.

In the domain-based approach, three domain-domain interaction (DDI) databases, namely 3did (three-dimensional interacting domains) [89], DOMINE (Database of Protein Domain Interactions) [90], and IDDI (integrated domain-domain interaction) [91], were executed locally. In order to predict the domain-domain interactions, the domains for pathogen and host proteins were fetched from the Pfam v31.0 [92] database and were then queried against the three DDI databases. The detailed information of the databases is available in Supplementary Material File S1 (Excel Sheet S1).

\subsection{Prediction of PPIs between T. aestivum and Tilletia Species \\ 3.2.1. Interolog-Based Prediction}

The interolog method, i.e., homology-based prediction of HPIs, is based on the conserved interactions between two proteins in one species that have interacting homologs in other species, i.e., inter-species predictions [93]. This conserved interaction is known as "Interolog". The analysis is carried out by performing a sequence alignment of the host and pathogen proteins against the seven respective databases (BioGRID, DIP, IntAct, HPIDB, MINT, STRING, and PHI-base) using BLAST v2.7.1 with default parameters (sequence identity, e-value, and sequence coverage), followed by the filtering of the alignments using an appropriate combination of BLAST parameters. For filtering the BLAST alignments, random combinations of sequence identity, e-value, and sequence coverage were generated, and an optimal combination was selected. Previously, there was no leading evidence reporting the standard cutoff for evaluating the BLAST parameters for the prediction of HPIs. In a study on Mycobacterium tuberculosis and Homo sapiens, researchers predicted HPIs by employing an e-value of 1 e-10 and sequence identity of 30\% [94]. Other researchers identified dynamic PPIs in cassava by using the following criteria: e-value $\leq 1 \times 10^{-10}$, percent identity $\geq 60 \%$, and percent coverage $\geq 80 \%$ in BLASTp sequence alignments [95].

\subsubsection{Domain-Based Prediction}

In this method, the domains, being the mediators of the interactions, are exploited to infer the PPIs in single organisms [96], i.e., unlike the interolog approach, this approach can be employed only for intra-species predictions. In order to predict HPIs, an algorithm integrates the protein domains with interactions between different proteins of the same organism, and this interaction is estimated using Bayesian statistics [93]. HMMER v3.3.1 (hmmscan), based on hidden Markov models (HMMs), was employed to delineate the domains for host and pathogen from the Pfam database. These domains were further queried locally in SQL for the prediction of PPIs. The filtering of the hmmscan results for $T$. aestivum was performed using an e-value and coverage of $1 \times 10^{-23}$ and 0.2 , respectively, while the filtering of the Tilletia species was performed using an e-value of $1 \times 10^{-17}$ and coverage of 0.45 . The domain-based prediction of PPIs using hmmscan has been successful in various studies $[97,98]$. 


\subsection{Prediction of Effector and Secretory Proteins}

Fungal effectors colonize the plant cell, overcome the plant immune system, and suppress the defense system by targeting specific host proteins [99]. Secretory proteins are short proteins that have signal peptides in their amino terminus, which help in translocating the proteins across the host plasma membrane and ultimately alter the host cell's physiological processes [100]. In view of this, we predicted the effector and secretory proteins in the T. caries and T. laevis datasets. To identify the proteins serving as effectors, the proteomes of both the species were analyzed on the EffectorP 2.0 web server (http:/ / effectorp.csiro.au/ (accessed on 23 April 2021)) [99], while the fungal secretory proteins were identified using the SignalP 5.0 tool (http:/ / www.cbs.dtu.dk/services/SignalP / (accessed on 23 April 2021)) [101].

\subsection{Functional Enrichment Analysis}

In order to determine the function/biological pathways of the proteins involved in the predicted HPIs, a functional annotation of the proteins in the predictions was performed. For functional enrichment, gene ontology (GO) and the Kyoto Encyclopedia of Genes and Genomes (KEGG) analyses were performed using the R package clusterProfiler [102]. For the GO enrichment of the host and pathogen proteins, the three GO annotation ontologies, i.e., biological process, cellular component, and molecular function, were considered using the Benjamini and Hochberg test correction method [103] at a $p$-value cutoff of $\leq 0.05$. KEGG enrichment for the proteins was also performed using the clusterProfiler package at a $p$-value cutoff of 0.05 .

\subsection{Subcellular Localization of the Predicted Proteins}

The various proteins synthesized in an organism are destined to perform a specialized function in a specific subcellular compartment of a cell [104]. Plant pathogens secrete effector proteins into host cells, which target specific cell compartments and further subvert the host mechanism to their advantage [105]. Thus, the determination of the subcellular localization of the host and pathogen proteins involved in the interactions is an essential step of the host-pathogen interaction analysis and provides the information about the location of the interactions between host and pathogen proteins. To predict the subcellular localization of the host proteins, we employed the SVM (support vector machine)-based model of Plant-mSubP tool [106]. The subcellular localization of the fungal proteins was predicted using the standalone version of DeepLoc 1.0, a deep learning-based tool for the prediction of eukaryotic protein localization [107].

\subsection{Comparison between HPIs of T. caries and T. laevis}

Since both the Tilletia species are highly similar, we decided to find the functional differences between the two fungal species. By comparing the HPIs, we found the proteins that serve as orthologs between T. caries and T. laevis. Due to the unavailability of a specific database for the Tilletia species, the orthologs were predicted using the standalone tool OrthoFinder [108], which provides a phylogenetic-based inference of orthologs between two species. Further, we identified the host proteins interacting with the orthologs. The common PPIs from both the species obtained using fungal protein orthologs and common host proteins were referred to as the common subnetwork, and the functional analysis was carried out using the common subnetwork. The pathogen proteins that were not predicted as orthologs, named as unique proteins, were analyzed separately to find the differences between the two fungal species.

\subsection{Network Visualization}

The generation of enormous interactome data from computational techniques has led to the need for robust analytical strategies to obtain deeper insights into the function of various elements of large-scale datasets [109]. Since proteins play a major role in various biological processes, the systematic study of the PPI network helps in deciphering the 
underlying cellular mechanisms in a diseased organism or in identifying novel protein targets. The protein interaction network abstracts the relationship between the function and network structure, depending on the functional and physical association [110]. In this study, the visualization of protein networks was carried out using cytoscape [111], the most widely used tool for network analysis. The networks were enhanced using different styles and yFiles layout algorithms in cytoscape and were further analyzed to determine the major protein hubs.

\section{Conclusions}

Host-pathogen interactions illustrate the mechanisms by which pathogens subvert host cellular processes and initiate an infection. The advancement in computational biology and bioinformatics has enabled researchers to extensively study large datasets at the genome-wide scale. Here, the interactome study between T. aestivum and the two Tilletia species postulated that protein-protein interactions between the host and pathogen forms the basis of disease infection. Using interolog-based and domain-based approaches, we predicted 5,075,732 common PPIs (from T. caries and T. laevis) involving 79,758 host and 423 pathogen proteins. From the protein hub analysis, we found that the most interconnected host hub was involved in the activity of serine/threonine protein kinases, MAPKKK, and the Hsp70 family, which have been reported to be implicated in defense signals during biotic stress. The GO and KEGG enrichment analysis of the host proteins showed significantly over-represented terms / pathways that play a role in plant defense against pathogens. These involved the GO terms O-methyltransferase activity (GO:0008171), hydroquinone:oxygen oxidoreductase activity (GO:0052716), plastid envelope (GO:0009526), chloroplast membrane (GO:0031969), regulation of signal transduction (GO:0009966), and the KEGG pathways NF-kappa B signaling (ko04064), plant-pathogen interaction (ko04626), plant hormone signal transduction (ko04075), calcium signaling pathway (ko04020), and others. On the other hand, the enrichment analysis of the pathogen proteins suggested that they were involved in virulence. The subcellular localization of the proteins involved in the HPIs exhibited different cellular sites where the host and pathogen proteins are localized. We also identified novel host proteins that serve as R-genes and transcription factors, which can be considered as potential candidates for understanding the common bunt infection mechanism. Various researchers in the past have identified bunt-resistance SNPs/QTLs on different chromosomes, thus validating our predicted PPIs. Furthermore, the data generated from experimental techniques (such as the yeast two-hybrid system and bimolecular fluorescence complementation) and transcriptomics can be integrated with the predicted PPIs, thus improving the quality of the interactome. We believe that the data generated from the current study will be of immense importance to the research community to gain in-depth knowledge of the host defense responses against pathogen attack.

Supplementary Materials: The supplementary material can be downloaded at: http:/ / biocluster. usu.edu/publications/rkataria/wheat_cb_PPIs/Suppementary_Material.

Author Contributions: R.K. (Rakesh Kaundal) formulated and designed the research. R.K. (Raghav Kataria) analyzed the data, developed prediction models, and performed functional enrichment analysis, validations, literature mining, etc. Writing-original draft preparation, R.K. (Raghav Kataria); writing - review and editing, R.K. (Rakesh Kaundal); visualization, R.K. (Raghav Kataria) and R.K. (Rakesh Kaundal); supervision, R.K. (Rakesh Kaundal); project administration, R.K. (Rakesh Kaundal); funding acquisition, R.K. (Rakesh Kaundal). All authors have read and agreed to the published version of the manuscript.

Funding: The authors acknowledge the support for this study from the Utah Agricultural Experiment Station (UAES), Utah State University, grant \#A48025 to R.K. This research was also supported by the UAES office and approved as journal paper number 9560. The funding body had no involvement in the design of this study; data collection, analysis, and interpretation; or article preparation.

Institutional Review Board Statement: Not applicable. 
Informed Consent Statement: Not applicable.

Data Availability Statement: Not applicable.

Acknowledgments: The authors are thankful to the members of KAABiL bioinformatics team (Utah State University) for their valuable inputs throughout the research analysis, and for access to the high-performance computing cluster.

Conflicts of Interest: The authors declare no conflict of interest.

\section{References}

1. Miransari, M.; Smith, D. Sustainable wheat (Triticum aestivum L.) production in saline fields: A review. Crit. Rev. Biotechnol. 2019, 39, 999-1014. [CrossRef]

2. Shewry, P.R.; Hey, S.J. The contribution of wheat to human diet and health. Food Energy Secur. 2015, 4, 178-202. [CrossRef]

3. Narayanan, S. Effects of high temperature stress and traits associated with tolerance in wheat. Open Access J. Sci. 2018, 2, 177-186. [CrossRef]

4. Figueroa, M.; Hammond-Kosack, K.E.; Solomon, P.S. A review of wheat diseases-A field perspective. Mol. Plant Pathol. 2018, 19, 1523-1536. [CrossRef]

5. Dean, R.; Van Kan, J.A.L.; Pretorius, Z.A.; Hammond-Kosack, K.E.; Di Pietro, A.; Spanu, P.D.; Rudd, J.J.; Dickman, M.; Kahmann, R.; Ellis, J.; et al. The Top 10 fungal pathogens in molecular plant pathology. Mol. Plant Pathol. 2012, 13, 414-430. [CrossRef] [PubMed]

6. McNeil, M.; Roberts, A.M.I.; Cockerell, V.; Mulholland, V. Real-time PCR assay for quantification of Tilletia caries contamination of UK wheat seed. Plant Pathol. 2004, 53, 741-750. [CrossRef]

7. Váňová, M.; Matušinsky, P.; Benada, J. Survey of Incidence of Bunts (Tilletia caries and Tilletia controversa) in the Czech Republic and Susceptibility of Winter Wheat Cultivars. Plant Prot. Sci. 2018, 42, 21-25. [CrossRef]

8. Cota, L.; Botez, C.; Grigoras, M.; Curticiu, D. Screening for Resistance to Artificial Infection by Common Bunt (Tilletia caries and Tilletia Foetida) in F2 Populations of Wheat (Triticum aestivum L.). Bull. Univ. Agric. Sci. Vet. Med. Cluj-Napoca 2009, 66, $24-31$.

9. Li, C.; Wei, X.; Gao, L.; Chen, W.; Liu, T.; Liu, B. iTRAQ-Based Proteomic Analysis of Wheat Bunt Fungi Tilletia controversa, T. caries, and T. foetida. Curr. Microbiol. 2018, 75, 1103-1107. [CrossRef] [PubMed]

10. Goates, B.J.; Bockelman, H.E. Identification of new sources of high levels of resistance to dwarf bunt and common bunt among winter wheat landraces in the USDA-ARS national small grains collection. Crop Sci. 2012, 52, 2595-2605. [CrossRef]

11. Chen, J.; Guttieri, M.J.; Zhang, J.; Hole, D.; Souza, E.; Goates, B. A novel QTL associated with dwarf bunt resistance in Idaho 444 winter wheat. Theor. Appl. Genet. 2016, 129, 2313-2322. [CrossRef]

12. Bonde, M.R.; Peterson, G.L.; Schaad, N.W.; Smilanick, J.L. Karnal bunt of wheat. Plant Dis. 1997, 81, 1370-1377. [CrossRef]

13. Mourad, A.; Mahdy, E.; Bakheit, B.R.; Abo-elwafaa, A.; Baenziger, P.S. Effect of common bunt infection on agronomic traits in wheat (Triticum aestivum L.). J. Plant Genet. Breed. 2018, 2, 1-7.

14. Pan, X.; Yang, Y.; Zhang, J.R. Molecular basis of host specificity in human pathogenic bacteria. Emerg. Microbes Infect. 2014, 3, 1-10. [CrossRef] [PubMed]

15. Gonzalez, M.W.; Kann, M.G. Chapter 4: Protein Interactions and Disease. PLoS Comput. Biol. 2012, 8, e1002819. [CrossRef] [PubMed]

16. Kotlyar, M.; Pastrello, C.; Pivetta, F.; Lo Sardo, A.; Cumbaa, C.; Li, H.; Naranian, T.; Niu, Y.; Ding, Z.; Vafaee, F.; et al. In silico prediction of physical protein interactions and characterization of interactome orphans. Nat. Methods 2014, 12, 79-84. [CrossRef]

17. Loaiza, C.D.; Duhan, N.; Lister, M.; Kaundal, R. In silico prediction of host-pathogen protein interactions in melioidosis pathogen Burkholderia pseudomallei and human reveals novel virulence factors and their targets. Brief. Bioinform. 2020, 22. [CrossRef]

18. Wang, F.; Liu, M.; Song, B.; Li, D.; Pei, H.; Guo, Y.; Huang, J.; Zhang, D. Prediction and characterization of protein-protein interaction networks in swine. Proteome Sci. 2012, 10, 2. [CrossRef]

19. Chen, P.Y.; Deane, C.M.; Reinert, G. Predicting and validating protein interactions using network structure. PLoS Comput. Biol. 2008, 4, e1000118. [CrossRef]

20. Ekman, D.; Light, S.; Björklund, Å.K.; Elofsson, A. What properties characterize the hub proteins of the protein-protein interaction network of Saccharomyces cerevisiae? Genome Biol. 2006, 7, R45. [CrossRef]

21. Charitou, T.; Bryan, K.; Lynn, D.J. Using biological networks to integrate, visualize and analyze genomics data. Genet. Sel. Evol. 2016, 48, 27. [CrossRef] [PubMed]

22. Ren, W.; Sang, C.; Shi, D.; Song, X.; Zhou, M.; Chen, C. Ubiquitin-like activating enzymes BcAtg3 and BcAtg7 participate in development and pathogenesis of Botrytis cinerea. Curr. Genet. 2018, 64, 919-930. [CrossRef] [PubMed]

23. Dautt-Castro, M.; Rosendo-Vargas, M.; Casas-Flores, S. The Small GTPases in Fungal Signaling Conservation and Function. Cells 2021, 10, 1039. [CrossRef] [PubMed]

24. Cheng, Y.; Yao, J.; Zhang, Y.; Li, S.; Kang, Z. Characterization of a Ran gene from Puccinia striiformis f. sp. tritici involved in fungal growth and anti-cell death. Sci. Rep. 2016, 6, 35248. [CrossRef] [PubMed] 
25. Heupel, S.; Roser, B.; Kuhn, H.; Lebrun, M.H.; Villalba, F.; Requena, N. Erl1, a novel era-like GTPase from Magnaporthe oryzae, is required for full root virulence and is conserved in the mutualistic symbiont Glomus intraradices. Mol. Plant Microbe Interact. 2010, 23, 67-81. [CrossRef] [PubMed]

26. Wang, G.; Li, G.; Zhang, S.; Jiang, C.; Qin, J.; Xu, J.R. Activation of the signalling mucin MoMsb2 and its functional relationship with Cbp1 in Magnaporthe oryzae. Environ. Microbiol. 2015, 17, 2969-2981. [CrossRef] [PubMed]

27. Lim, Y.J.; Kim, K.T.; Lee, Y.H. SUMOylation is required for fungal development and pathogenicity in the rice blast fungus Magnaporthe oryzae. Mol. Plant Pathol. 2018, 19, 2134-2148. [CrossRef] [PubMed]

28. Fan, X.; He, F.; Ding, M.; Geng, C.; Chen, L.; Zou, S.; Liang, Y.; Yu, J.; Dong, H. Thioredoxin reductase is involved in development and pathogenicity in Fusarium graminearum. Front. Microbiol. 2019, 10, 393. [CrossRef]

29. Zhang, J.; Cui, W.; Abdul Haseeb, H.; Guo, W. VdNop12, containing two tandem RNA recognition motif domains, is a crucial factor for pathogenicity and cold adaption in Verticillium dahliae. Environ. Microbiol. 2020, 22, 5387-5401. [CrossRef] [PubMed]

30. Becht, P.; Vollmeister, E.; Feldbrügge, M. Role for RNA-binding proteins implicated in pathogenic development of Ustilago maydis. Eukaryot. Cell 2005, 4, 121-133. [CrossRef] [PubMed]

31. Wang, Y.; Yan, H.; Qiu, Z.; Hu, B.; Zeng, B.; Zhong, C.; Fan, C. Comprehensive analysis of SNRK gene family and their responses to salt stress in Eucalyptus grandis. Int. J. Mol. Sci. 2019, 20, 2786. [CrossRef] [PubMed]

32. Zhou, J.; Loh, Y.T.; Bressan, R.A.; Martin, G.B. The tomato gene Pti1 encodes a serine/threonine kinase that is phosphorylated by Pto and is involved in the hypersensitive response. Cell 1995, 83, 925-935. [CrossRef]

33. Lee, J.H.; Yun, H.S.; Kwon, C. Molecular communications between plant heat shock responses and disease resistance. Mol. Cells 2012, 34, 109-116. [CrossRef] [PubMed]

34. Alam, S.B.; Rochon, D. Cucumber Necrosis Virus Recruits Cellular Heat Shock Protein 70 Homologs at Several Stages of Infection. J. Virol. 2016, 90, 3302-3317. [CrossRef] [PubMed]

35. Ho, H.L. Functional Roles of Plant Protein Kinases in Signal Transduction Pathways during Abiotic and Biotic Stress. J. Biodivers. Bioprospecting Dev. 2015, 2. [CrossRef]

36. Asano, T.; Nguyen, T.H.N.; Yasuda, M.; Sidiq, Y.; Nishimura, K.; Nakashita, H.; Nishiuchi, T. Arabidopsis MAPKKK $\delta-1$ is required for full immunity against bacterial and fungal infection. J. Exp. Bot. 2020, 71, 2085-2097. [CrossRef] [PubMed]

37. Shou, H.; Bordallo, P.; Wang, K. Expression of the Nicotiana protein kinase (NPK1) enhanced drought tolerance in transgenic maize. J. Exp. Bot. 2004, 55, 1013-1019. [CrossRef] [PubMed]

38. Kovtun, Y.; Chiu, W.L.; Tena, G.; Sheen, J. Functional analysis of oxidative stress-activated mitogen-activated protein kinase cascade in plants. Proc. Natl. Acad. Sci. USA 2000, 97, 2940-2945. [CrossRef] [PubMed]

39. Ma, X.; Gai, W.X.; Qiao, Y.M.; Ali, M.; Wei, A.M.; Luo, D.X.; Li, Q.H.; Gong, Z.H. Identification of CBL and CIPK gene families and functional characterization of CaCIPK1 under Phytophthora capsici in pepper (Capsicum annuum L.). BMC Genom. 2019, 20, 775. [CrossRef] [PubMed]

40. Liu, P.; Guo, J.; Zhang, R.; Zhao, J.; Liu, C.; Qi, T.; Duan, Y.; Kang, Z.; Guo, J. TaCIPK10 interacts with and phosphorylates TaNH2 to activate wheat defense responses to stripe rust. Plant Biotechnol. J. 2019, 17, 956-968. [CrossRef]

41. Zhu, X.; Yang, K.; Wei, X.; Zhang, Q.; Rong, W.; Du, L.; Ye, X.; Qi, L.; Zhang, Z. The wheat AGC kinase TaAGC1 is a positive contributor to host resistance to the necrotrophic pathogen Rhizoctonia cerealis. J. Exp. Bot. 2015, 66, 6591-6603. [CrossRef] [PubMed]

42. Pinter, N.; Hach, C.A.; Hampel, M.; Rekhter, D.; Zienkiewicz, K.; Feussner, I.; Poehlein, A.; Daniel, R.; Finkernagel, F.; Heimel, K. Signal peptide peptidase activity connects the unfolded protein response to plant defense suppression by Ustilago maydis. PloS Pathog. 2019, 15, e1007734. [CrossRef] [PubMed]

43. Pogány, M.; Dankó, T.; Kámán-Tóth, E.; Schwarczinger, I.; Bozsó, Z. Regulatory proteolysis in Arabidopsis-Pathogen interactions. Int. J. Mol. Sci. 2015, 16, 23177-23194. [CrossRef]

44. Devoto, A.; Muskett, P.R.; Shirasu, K. Role of ubiquitination in the regulation of plant defence against pathogens. Curr. Opin. Plant Biol. 2003, 6, 307-311. [CrossRef]

45. Wang, S.; Cao, L.; Wang, H. Arabidopsis ubiquitin-conjugating enzyme UBC22 is required for female gametophyte development and likely involved in Lys11-linked ubiquitination. J. Exp. Bot. 2016, 67, 3277-3288. [CrossRef]

46. Balasubramanian, V.; Vashisht, D.; Cletus, J.; Sakthivel, N. Plant $\beta$-1,3-glucanases: Their biological functions and transgenic expression against phytopathogenic fungi. Biotechnol. Lett. 2012, 34, 1983-1990. [CrossRef]

47. Aggarwal, R.; Purwar, S.; Kharbikar, L.; Gupta, S. Induction of a wheat $\beta$-1,3-glucanase gene during the defense response to Bipolaris sorokiniana. Acta Phytopathol. Entomol. Hung. 2011, 46, 39-47. [CrossRef]

48. Breuers, F.K.H.; Bräutigam, A.; Weber, A.P.M. The plastid outer envelope-A highly dynamic interface between plastid and cytoplasm. Front. Plant Sci. 2011, 2, 97. [CrossRef]

49. Howe, G.A.; Schilmiller, A.L. Oxylipin metabolism in response to stress. Curr. Opin. Plant Biol. 2002, 5, 230-236. [CrossRef]

50. Kishimoto, K.; Matsui, K.; Ozawa, R.; Takabayashi, J. Direct fungicidal activities of C6-aldehydes are important constituents for defense responses in Arabidopsis against Botrytis cinerea. Phytochemistry 2008, 69, 2127-2132. [CrossRef]

51. Ferro, M.; Salvi, D.; Brugière, S.; Miras, S.; Kowalski, S.; Louwagie, M.; Garin, J.; Joyard, J.; Rolland, N. Proteomics of the chloroplast envelope membranes from Arabidopsis thaliana. Mol. Cell. Proteom. 2003, 2, 325-345. [CrossRef] [PubMed]

52. Fritsche, S.; Wang, X.; Jung, C. Recent advances in our understanding of tocopherol biosynthesis in plants: An overview of key genes, functions, and breeding of vitamin E improved crops. Antioxidants 2017, 6, 99. [CrossRef] [PubMed] 
53. Nosek, M.; Kornaś, A.; Kuźniak, E.; Miszalski, Z. Plastoquinone redox state modifies plant response to pathogen. Plant Physiol. Biochem. 2015, 96, 163-170. [CrossRef]

54. Liu, Z.; Fan, M.; Li, C.; Xu, J.H. Dynamic gene amplification and function diversification of grass-specific O-methyltransferase gene family. Genomics 2019, 111, 687-695. [CrossRef] [PubMed]

55. Bhuiyan, N.H.; Selvaraj, G.; Wei, Y.; King, J. Gene expression profiling and silencing reveal that monolignol biosynthesis plays a critical role in penetration defence in wheat against powdery mildew invasion. J. Exp. Bot. 2009, 60, 509-521. [CrossRef]

56. Wang, M.; Zhu, X.; Wang, K.; Lu, C.; Luo, M.; Shan, T.; Zhang, Z. A wheat caffeic acid 3-O-methyltransferase TaCOMT-3D positively contributes to both resistance to sharp eyespot disease and stem mechanical strength. Sci. Rep. 2018, 8, 6543. [CrossRef] [PubMed]

57. Heyno, E.; Alkan, N.; Fluhr, R. A dual role for plant quinone reductases in host-fungus interaction. Physiol. Plant. 2013, 149, 340-353. [CrossRef] [PubMed]

58. Zhao, M.; Joy, J.; Zhou, W.; De, S.; Wood, W.H.; Becker, K.G.; Ji, H.; Sen, R. Transcriptional outcomes and kinetic patterning of gene expression in response to NF-KB activation. PLoS Biol. 2018, 16, e2006347. [CrossRef]

59. Ryals, J.; Weymann, K.; Lawton, K.; Friedrich, L.; Ellis, D.; Steiner, H.Y.; Johnson, J.; Delaney, T.P.; Jesse, T.; Vos, P.; et al. The arabidopsis NIM1 protein shows homology to the mammalian transcription factor inhibitor IkB. Plant Cell 1997, 9, 425-439. [CrossRef]

60. Hiscott, J.; Nguyen, T.L.A.; Arguello, M.; Nakhaei, P.; Paz, S. Manipulation of the nuclear factor-kB pathway and the innate immune response by viruses. Oncogene 2006, 25, 6844-6867. [CrossRef]

61. Zhang, S.; Klessig, D.F. MAPK cascades in plant defense signaling. Trends Plant Sci. 2001, 6, 520-527. [CrossRef]

62. Jalmi, S.K.; Sinha, A.K. Functional Involvement of a Mitogen Activated Protein Kinase Module, OsMKK3-OsMPK7-OsWRK30 in Mediating Resistance against Xanthomonas oryzae in Rice. Sci. Rep. 2016, 6, 37974. [CrossRef] [PubMed]

63. Drawid, A.; Gerstein, M. A Bayesian system integrating expression data with sequence patterns for localizing proteins: Comprehensive application to the yeast genome. J. Mol. Biol. 2000, 301, 1059-1075. [CrossRef] [PubMed]

64. Wang, J.; Li, C.; Wang, E.; Wang, X. An FPT approach for predicting protein localization from yeast genomic data. PLoS ONE 2011, 6, e14449. [CrossRef]

65. Pedrajas, J.R.; Kosmidou, E.; Miranda-Vizuete, A.; Gustafsson, J.Å.; Wright, A.P.H.; Spyrou, G. Identification and functional characterization of a novel mitochondrial thioredoxin system in Saccharomyces cerevisiae. J. Biol. Chem. 1999, 274, 6366-6373. [CrossRef] [PubMed]

66. Trotter, E.W.; Grant, C.M. Overlapping roles of the cytoplasmic and mitochondrial redox regulatory systems in the yeast Saccharomyces cerevisiae. Eukaryot. Cell 2005, 4, 392-400. [CrossRef] [PubMed]

67. Kim, D.Y.; Kwon, S.I.; Choi, C.; Lee, H.; Ahn, I.; Park, S.R.; Bae, S.C.; Lee, S.C.; Hwang, D.J. Expression analysis of rice VQ genes in response to biotic and abiotic stresses. Gene 2013, 529, 208-214. [CrossRef] [PubMed]

68. Huberts, D.H.E.W.; van der Klei, I.J. Moonlighting proteins: An intriguing mode of multitasking. Biochim. Biophys. Acta Mol. Cell Res. 2010, 1803, 520-525. [CrossRef] [PubMed]

69. Song, T.; Zhao, J.; Ying, S.; Feng, M. Differential Contributions of Five ABC Transporters to Mutidrug Resistance, Antioxidion and Virulence of Beauveria bassiana, an Entomopathogenic Fungus. PLoS ONE 2013, 8, e62179. [CrossRef] [PubMed]

70. Floryszak-wieczorek, J.; Gajewska, J.; Gzyl, J.; Jelonek, T.; Arasimowicz-jelonek, M. Switchable Nitroproteome States of Phytophthora infestans Biology and Pathobiology. Front. Microbiol. 2019, 10, 1516. [CrossRef]

71. Hu, Y.; Elfstrand, M.; Stenlid, J.; Durling, M.B.; Olson, A. The conifer root rot pathogens Heterobasidion irregulare and Heterobasidion occidentale employ different strategies to infect Norway spruce. Sci. Rep. 2020, 10, 5884. [CrossRef]

72. Wang, H.; Wei, S.; Yang, X.; Liu, W. Proteomic analysis of exudate of Cercospora armoraciae from Armoracia rusticana. PeerJ 2020, 8 , e9592. [CrossRef] [PubMed]

73. Andersen, E.; Lindsey, L.; Nepal, M. Genome-wide Identification of Disease Resistance Genes (R Genes) in Wheat. bioRxiv 2020. [CrossRef]

74. Bhatta, M.; Morgounov, A.; Belamkar, V.; Yorgancllar, A.; Baenziger, P.S. Genome-wide association study reveals favorable alleles associated with common bunt resistance in synthetic hexaploid wheat. Euphytica 2018, 214, 200. [CrossRef]

75. Mourad, A.M.I.; Sallam, A.; Belamkar, V.; Mahdy, E.; Bakheit, B.; Abo El-Wafaa, A.; Stephen Baenziger, P. Genetic architecture of common bunt resistance in winter wheat using genome-wide association study. BMC Plant Biol. 2018, 18, 280. [CrossRef]

76. Muellner, A.E.; Buerstmayr, M.; Eshonkulov, B.; Hole, D.; Michel, S.; Hagenguth, J.F.; Pachler, B.; Pernold, R.; Buerstmayr, H. Comparative mapping and validation of multiple disease resistance QTL for simultaneously controlling common and dwarf bunt in bread wheat. Theor. Appl. Genet. 2021, 134, 489-503. [CrossRef] [PubMed]

77. Hafeez, A.N.; Arora, S.; Ghosh, S.; Gilbert, D.; Bowden, R.L.; Wulff, B.B.H. Creation and judicious application of a wheat resistance gene atlas. Mol. Plant 2021, 14, 1053-1070. [CrossRef]

78. Baillo, E.H.; Kimotho, R.N.; Zhang, Z.; Xu, P. Transcription factors associated with abiotic and biotic stress tolerance and their potential for crops improvement. Genes 2019, 10, 771. [CrossRef]

79. Ng, D.W.K.; Abeysinghe, J.K.; Kamali, M. Regulating the regulators: The control of transcription factors in plant defense signaling Int. J. Mol. Sci. 2018, 19, 3737. [CrossRef]

80. Yuan, X.; Wang, H.; Cai, J.; Li, D.; Song, F. NAC transcription factors in plant immunity. Phytopathol. Res. 2019, 1, 3. [CrossRef] 
81. Fu, L.; Niu, B.; Zhu, Z.; Wu, S.; Li, W. CD-HIT: Accelerated for clustering the next-generation sequencing data. Bioinformatics 2012, 28, 3150-3152. [CrossRef] [PubMed]

82. Kerrien, S.; Aranda, B.; Breuza, L.; Bridge, A.; Broackes-Carter, F.; Chen, C.; Duesbury, M.; Dumousseau, M.; Feuermann, M.; Hinz, U.; et al. The IntAct molecular interaction database in 2012. Nucleic Acids Res. 2012, 40, 841-846. [CrossRef] [PubMed]

83. Licata, L.; Briganti, L.; Peluso, D.; Perfetto, L.; Iannuccelli, M.; Galeota, E.; Sacco, F.; Palma, A.; Nardozza, A.P.; Santonico, E.; et al. MINT, the molecular interaction database: 2012 Update. Nucleic Acids Res. 2012, 40, 857-861. [CrossRef] [PubMed]

84. Kumar, R.; Nanduri, B. HPIDB-A unified resource for host-pathogen interactions. BMC Bioinform. 2010, 11, 16. [CrossRef]

85. Salwinski, L.; Miller, C.S.; Smith, A.J.; Pettit, F.K.; Bowie, J.U.; Eisenberg, D. The Database of Interacting Proteins: 2004 update. Nucleic Acids Res. 2004, 32, 449-451. [CrossRef]

86. Chatr-Aryamontri, A.; Oughtred, R.; Boucher, L.; Rust, J.; Chang, C.; Kolas, N.K.; O’Donnell, L.; Oster, S.; Theesfeld, C.; Sellam, A.; et al. The BioGRID interaction database: 2017 update. Nucleic Acids Res. 2017, 45, D369-D379. [CrossRef]

87. Szklarczyk, D.; Gable, A.L.; Lyon, D.; Junge, A.; Wyder, S.; Huerta-Cepas, J.; Simonovic, M.; Doncheva, N.T.; Morris, J.H.; Bork, P.; et al. STRING v11: Protein-protein association networks with increased coverage, supporting functional discovery in genome-wide experimental datasets. Nucleic Acids Res. 2019, 47, D607-D613. [CrossRef]

88. Urban, M.; Cuzick, A.; Seager, J.; Wood, V.; Rutherford, K.; Venkatesh, S.Y.; De Silva, N.; Martinez, M.C.; Pedro, H.; Yates, A.D.; et al. PHI-base: The pathogen-host interactions database. Nucleic Acids Res. 2020, 48, D613-D620. [CrossRef]

89. Mosca, R.; Céol, A.; Stein, A.; Olivella, R.; Aloy, P. 3did: A catalog of domain-based interactions of known three-dimensional structure. Nucleic Acids Res. 2014, 42, 374-379. [CrossRef]

90. Raghavachari, B.; Tasneem, A.; Przytycka, T.M.; Jothi, R. DOMINE: A database of protein domain interactions. Nucleic Acids Res. 2008, 36, 656-661. [CrossRef]

91. Kim, Y.; Min, B.; Yi, G.S. IDDI: Integrated domain-domain interaction and protein interaction analysis system. Proteome Sci. 2012, 10, S9. [CrossRef] [PubMed]

92. Finn, R.D.; Bateman, A.; Clements, J.; Coggill, P.; Eberhardt, R.Y.; Eddy, S.R.; Heger, A.; Hetherington, K.; Holm, L.; Mistry, J.; et al Pfam: The protein families database. Nucleic Acids Res. 2014, 42, 222-230. [CrossRef] [PubMed]

93. Nourani, E.; Khunjush, F.; Durmus, S. Computational approaches for prediction of pathogen-host protein-protein interactions. Front. Microbiol. 2015, 6, 94. [CrossRef]

94. Huo, T.; Liu, W.; Guo, Y.; Yang, C.; Lin, J.; Rao, Z. Prediction of host-pathogen protein interactions between Mycobacterium tuberculosis and Homo sapiens using sequence motifs. BMC Bioinform. 2015, 16, 100. [CrossRef]

95. Thanasomboon, R.; Kalapanulak, S.; Netrphan, S.; Saithong, T. Exploring dynamic protein-protein interactions in cassava through the integrative interactome network. Sci. Rep. 2020, 10, 6510. [CrossRef] [PubMed]

96. Wojcik, J.; Schächter, V. Protein-protein interaction map inference using interacting domain profile pairs. Bioinformatics 2001, 17 (Suppl. S1), S296-S305. [CrossRef] [PubMed]

97. Mondal, S.I.; Mahmud, Z.; Elahi, M.; Akter, A.; Jewel, N.A.; Muzahidul Islam, M.; Ferdous, S.; Kikuchi, T. Study of intra-inter species protein-protein interactions for potential drug targets identification and subsequent drug design for Escherichia coli O104:H4 C277-11. In Silico Pharmacol. 2017, 5, 1. [CrossRef]

98. Lian, X.; Yang, X.; Shao, J.; Hou, F.; Yang, S.; Pan, D.; Zhang, Z. Prediction and analysis of human-herpes simplex virus type 1 protein-protein interactions by integrating multiple methods. Quant. Biol. 2020, 8, 312-324. [CrossRef]

99. Sperschneider, J.; Dodds, P.N.; Gardiner, D.M.; Singh, K.B.; Taylor, J.M. Improved prediction of fungal effector proteins from secretomes with EffectorP 2.0. Mol. Plant Pathol. 2018, 19, 2094-2110. [CrossRef] [PubMed]

100. Feldman, D.; Yarden, O.; Hadar, Y. Seeking the Roles for Fungal Small-Secreted Proteins in Affecting Saprophytic Lifestyles. Front. Microbiol. 2020, 11, 455. [CrossRef] [PubMed]

101. Almagro Armenteros, J.J.; Tsirigos, K.D.; Sønderby, C.K.; Petersen, T.N.; Winther, O.; Brunak, S.; von Heijne, G.; Nielsen, H. SignalP 5.0 improves signal peptide predictions using deep neural networks. Nat. Biotechnol. 2019, 37, 420-423. [CrossRef] [PubMed]

102. Yu, G.; Wang, L.G.; Han, Y.; He, Q.Y. ClusterProfiler: An R package for comparing biological themes among gene clusters. Omics J. Integr. Biol. 2012, 16, 284-287. [CrossRef] [PubMed]

103. Benjamini, Y.; Hochberg, Y. Controlling the False Discovery Rate: A Practical and Powerful Approach to Multiple Testing. J. R. Stat. Soc. Ser. B 1995, 57, 289-300. [CrossRef]

104. Dönnes, P.; Höglund, A. Predicting protein subcellular localization: Past, present, and future. Genom. Proteom. Bioinform. 2004, 2 , 209-215. [CrossRef]

105. Sperschneider, J.; Catanzariti, A.M.; Deboer, K.; Petre, B.; Gardiner, D.M.; Singh, K.B.; Dodds, P.N.; Taylor, J.M. LOCALIZER: Subcellular localization prediction of both plant and effector proteins in the plant cell. Sci. Rep. 2017, 7, rep44598. [CrossRef]

106. Sahu, S.S.; Loaiza, C.D.; Kaundal, R. Plant-mSubP: A computational framework for the prediction of single- and multi-target protein subcellular localization using integrated machine-learning approaches. AoB Plants 2020, 12, plz068. [CrossRef] [PubMed]

107. Almagro Armenteros, J.J.; Sønderby, C.K.; Sønderby, S.K.; Nielsen, H.; Winther, O. DeepLoc: Prediction of protein subcellular localization using deep learning. Bioinformatics 2017, 33, 3387-3395. [CrossRef] [PubMed]

108. Emms, D.M.; Kelly, S. OrthoFinder: Phylogenetic orthology inference for comparative genomics. Genome Biol. 2019, 20, 238. [CrossRef] [PubMed]

109. Ramos, P.I.P.; Arge, L.W.P.; Lima, N.C.B.; Fukutani, K.F.; de Queiroz, A.T.L. Leveraging User-Friendly Network Approaches to Extract Knowledge from High-Throughput Omics Datasets. Front. Genet. 2019, 10, 1120. [CrossRef] 
110. Safari-Alighiarloo, N.; Taghizadeh, M.; Rezaei-Tavirani, M.; Goliaei, B.; Peyvandi, A.A. Protein-protein interaction networks (PPI) and complex diseases. Gastroenterol. Hepatol. Bed Bench 2014, 7, 17-31. [CrossRef] [PubMed]

111. Shannon, P.; Markiel, A.; Ozier, O.; Baliga, N.S.; Wang, J.T.; Ramage, D.; Amin, N.; Schwikowski, B.; Ideker, T. Cytoscape: A Software Environment for Integrated Models. Genome Res. 2003, 13, 2498-2504. [CrossRef] [PubMed] 